

\section{DISCLAIMER}

Portions of this document may be illegible in electronic image products. Images are produced from the best available original document. 


\title{
FINAL REPORT FOR CONFINEMENT VESSEL ANALYSIS
}

\author{
TASK 2
}

SAFETY VESSEL IMPACT ANALYSIS

Yvonne D. Murray

APTEK, Inc.

January 26, 1994 


\title{
FINAL REPORT FOR CONFINEMENT VESSEL ANALYSIS TASK 2 SAFETY VESSEL IMPACT ANALYSES
}

\author{
Yvonne D. Murray \\ APTEK, Inc \\ January 26,1994
}

This report describes two sets of finite element analyses performed under Task 2 of the Confinement Vessel Analysis Program, subcontract number 9-XH3-0607K-1. In each set of analyses, a charge is assumed to have detonated inside the confinement vessel, causing the confinement vessel to fail in either of two ways; locally around the weld line of a nozzle, or catastrophically into two hemispheres. High pressure gases from the internal detonation pressurize the inside of the safety vessel and accelerate the fractured nozzle or hemisphere into the safety vessel.

The first set of analyses examines the structural integrity of the safety vessel when impacted by the fractured nozzle. The objective of these calculations is to determine if the high strength bolt heads attached to the nozzle penetrate or fracture the lower strength safety vessel, thus allowing gaseous detonation products to escape to the atmosphere. We simplified the complex three-dimensional geometry of the nozzle to two dimensions, modeling sharp and blunt penetrators to provide upper and lower bounds on the predicted response. The two dimensional analyses predict partial penetration of the safety vessel beneath the tip of the penetrator. The analyses also predict maximum principal strains in the safety vessel which exceed the measured ultimate strain of steel. Additional analyses in plane strain or three dimensions are recommended to remove conservatisms.

The second set of analyses examines the containment capability of the safety vessel closure when impacted by half a confinement vessel (hemisphere). The objective of these calculations is to determine if the closure mechanism allows the impact to form a gap between the two halves of the safety vessel, thus providing a escape path for gaseous detonation products. The predicted response is the formation of a 0.6-inch gap, caused by relative sliding and separation between the two halves of the safety vessel. Additional analyses with closure designs that prevent the gap formation are recommended. 


\section{Nozzle Impact Analysis}

Two finite element calculations of the nozzle penetrating the safety vessel were performed with the DYNA2D code. The objective of these calculations was to assess the structural integrity of the safety vessel by calculating the penetration depth and maximum principal strains in the safety vessel. Our concern is whether the high strength bolt heads attached to the nozzle would penetrate the lower strength safety vessel.

Although the impact of the safety vessel by the nozzle assembly is not an axisymmetric (two-dimensional) problem, we choose to simplify the problem to two dimensions so that the Arbitrary Lagrangian Eulerian (ALE) technique in DYNA2D could be used to perform the analysis. ALE is an automated technique for reducing mesh distortion, such as the severe distortions calculated in a medium penetrated by a sharp projectile. Without the use of ALE, the mesh beneath the penetrator would become highly distorted. Severe mesh distortions reduce computational accuracy, and in some cases, prevent completion of the analysis. ALE is not currently available in the three-dimensional DYNA3D code.

To perform a penetration analysis, the shape and initial velocity of the penetrator must be determined. Two axisymmetric penetrator models for the nozzle assembly are given in Section 1.1. These models are of sharp and blunt penetrators, and are intended to provide upper and lower bounds on the penetration depth, respectively. Our estimate for the initial velocity of the penetrator is given in Section 1.2. We analyzed the flow of pressurized gas from the confinement vessel to the safety vessel to calculate the acceleration history of the nozzle. Material properties and a brief description of the ALE technique are given in Section 1.3. Finally, deformed configurations for the safety vessel and contours of strain are given in Section 1.4. Large strains between 36 and 96 percent are predicted in the safety vessel, suggesting possible failure of the safety vessel.

\subsection{Axisymmetric Models of the Nozzle Assembly}

Two schematic views of the nozzle assembly are shown in Figure 1. The nozzle contains 64 bolts, with 1-1/2 inch diameter bolt heads, which attach it to the confinement vessel. A cross section along the diameter of the nozzle is shown in Figure 1a. We assume that the nozzle assembly approaches the safety vessel at 45 degrees to the normal of the safety vessel, so that the edge of one bolt head impacts the safety vessel before the edge of the nozzle. From this view, the bolt head is a sharp penetrator with a 90 degree tip. A front view of the nozzle face is shown in Figure 1b. This view is obtained by rotating the side view (previously shown in Figure 1a) 90 degrees about the ' $z$ ' axis. From this view, the bolt head is an elliptical, or blunt penetrator. These two views of the nozzle assembly form the bases of our axisymmetric penetrator models.

Full views and close-ups of two penetrator models impacting the safety vessel are shown in Figures 2 and 3. These views show one slice through the axisymmetric mesh. Only one half of the safety vessel was modeled because a plane of symmetry was assumed along the horizontal mid-plane through the vessel. The safety vessel 


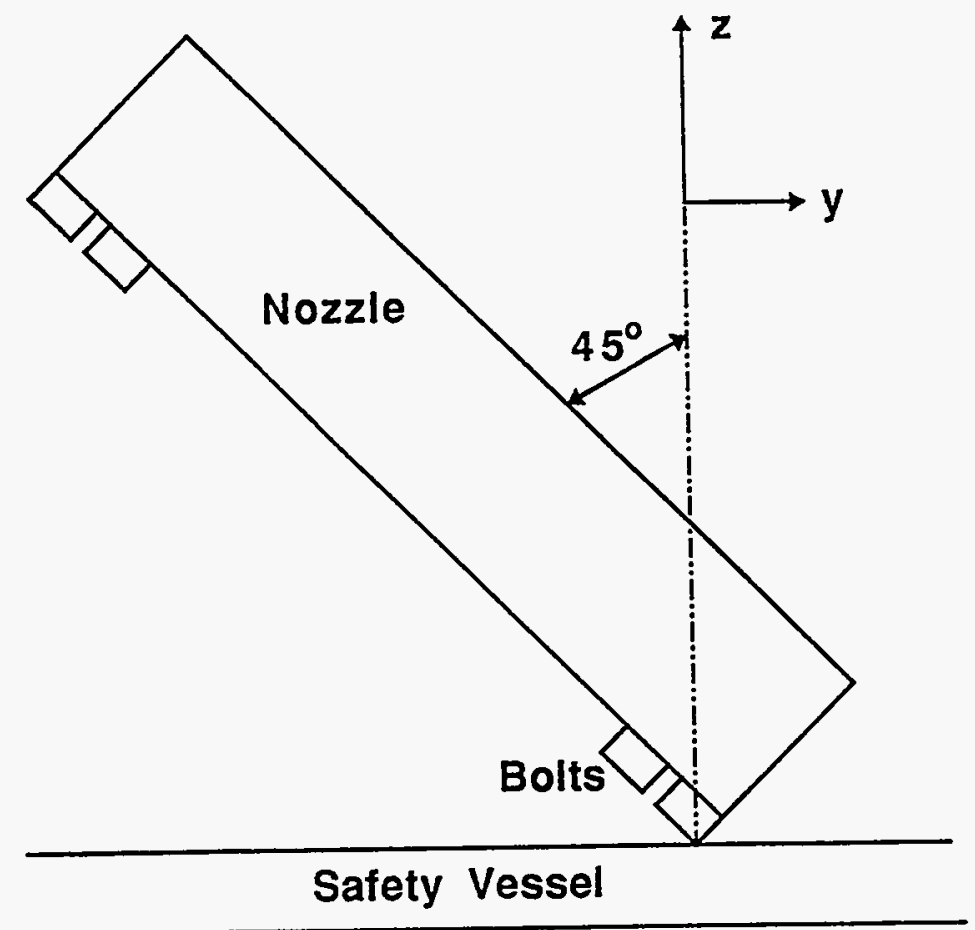

(a) Side view.

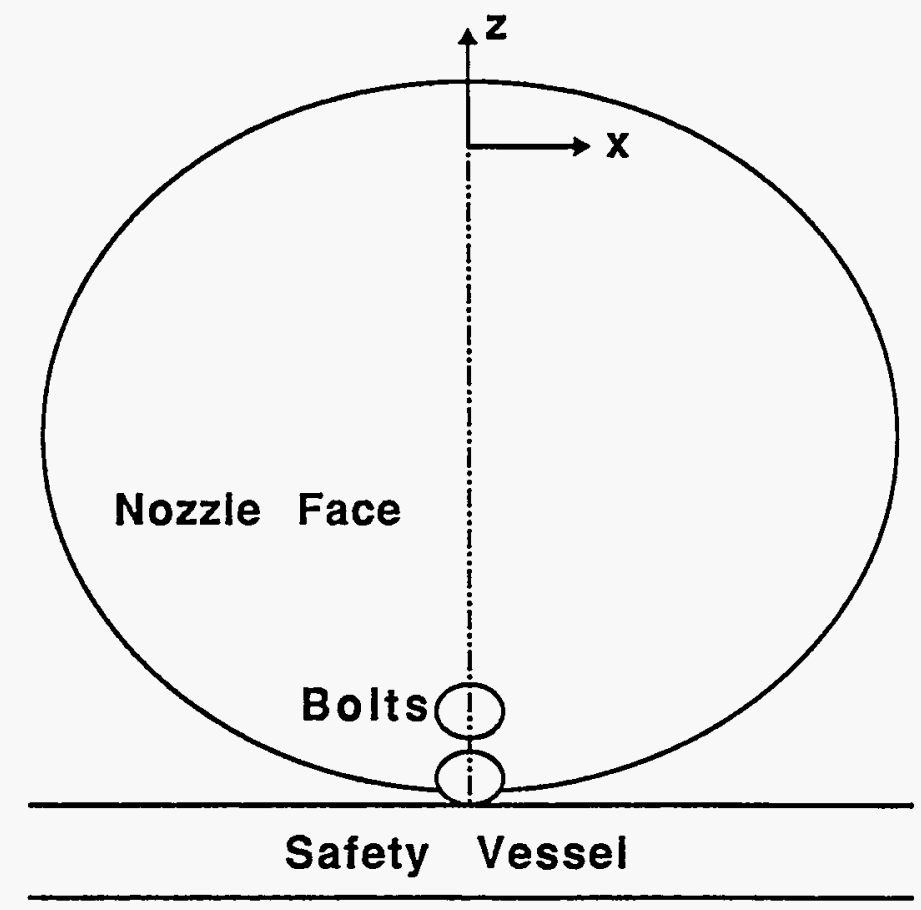

(b) Front view.

Figure 1: Two views of the bolt head and nozzle (penetrator) impacting the safety vessel. 
mesh is refined in the vicinity of the penetrator impact because we expected the most deformation in this region.

The shape of the penetrator in Figure 2 has been idealized as an axisymmetric cone, with the 90 degree tip of the cone representing the bolt head. This model is an axisymmetric representation of the cross section previously shown in Figure 1a. The mass of the cone is equal to the mass of the nozzle, which is assumed to have fractured around the weld line. This axisymmetric penetrator is sharper than the actual nozzle assembly, so we expect the finite element analysis to provide an upper bound estimate of the penetration depth. The shape of the penetrator tip in Figure 3 has been idealized as two axisymmetric elliptical sections. The smaller elliptical section represents one bolt head while the larger elliptical section represents the nozzle. This model is an axisymmetric representation of the bolt head and nozzle face previously shown in Figure $1 \mathrm{~b}$. The total mass of these sections is equal to the mass of the nozzle assembly. This penetrator is blunter than the three-dimensional nozzle assembly, so we expect the finite element analysis to provide a lower bound estimate of the penetration depth.

\subsection{Initial Velocity of the Penetrator}

The penetrator in each calculation was given an initial velocity, and the calculations were run until the velocity of the penetrator was reduced to zero. We estimated an initial velocity of $2015 \mathrm{in} / \mathrm{sec}$ from a simple gas dynamics analysis. We analyzed the flow of gas (explosive detonation products) from one chamber (the confinement vessel) to a second chamber (the safety vessel) through an orifice of variable area (the fractured nozzle). The orifice area increases as the fractured nozzle separates from the confinement vessel, thus allowing the gases to flow into the safety vessel and the pressure on each side of the nozzle to equalize. The acceleration history of the nozzle was calculated from the difference in pressure in each chamber. Details and verification of the analysis are given in Appendices $A$ and $B$.

The initial conditions and volumes of each chamber are given in Table 1 . The initial pressure in chamber 1 is the quasi-static pressure from an $40 \mathrm{lb}$ charge. The initial volume of chamber 1 is the volume within the confinement vessel. The initial pressure in chamber 2 is atmospheric pressure. The initial volume of chamber 2 is the difference in volume contained by the safety and confinement vessels. A gas constant of $\gamma=1.4$ was estimated for the explosive products from Reference [1] and was used in both chambers. We assumed that the nozzle broke at the weld line at a radius of 17 inches and estimated a total nozzle mass of $3.96 \mathrm{lb}-\mathrm{s}^{2} / \mathrm{in}$.

Chamber pressures, nozzle displacement, and velocity histories are given in Figures 4-6. The pressure in each chamber equalizes to about $810 \mathrm{psi}$ in 8 msecs. At this time, the nozzle displacement is over 10 inches and the nozzle velocity is steady at $2015 \mathrm{in} / \mathrm{sec}$. The nozzle acceleration is zero.

The velocity at which the nozzle impacts the safety vessel depends on the initial distance between the nozzle and safety vessel. This distance is approximately 9 inches. From Figure 5, we see that the nozzle attains a displacement of 9 inches in about 7.5 msecs. At this time the velocity is close to its assymtoptic value of $2015 \mathrm{in} / \mathrm{s}$ and the 


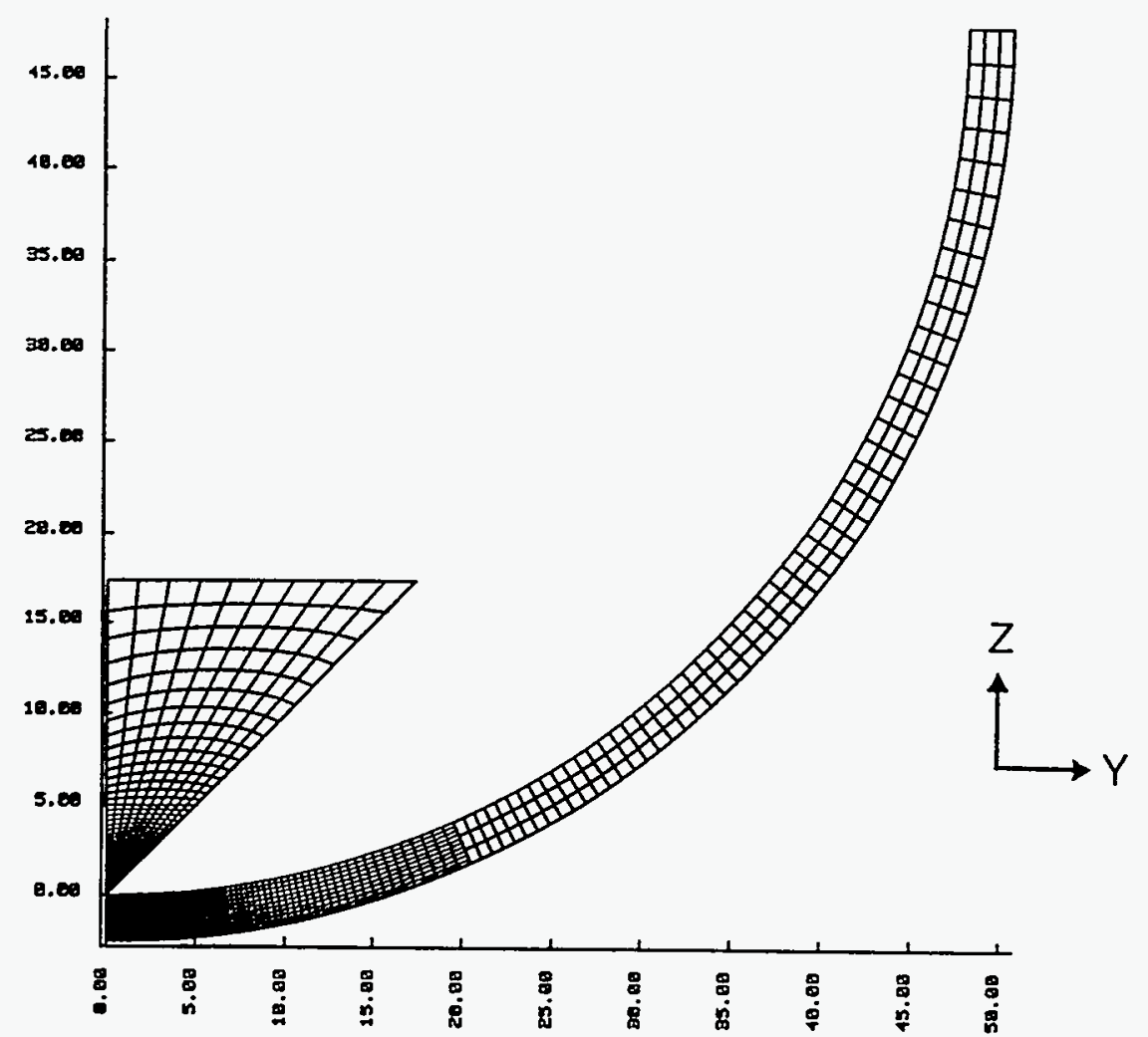

(a) Full view.

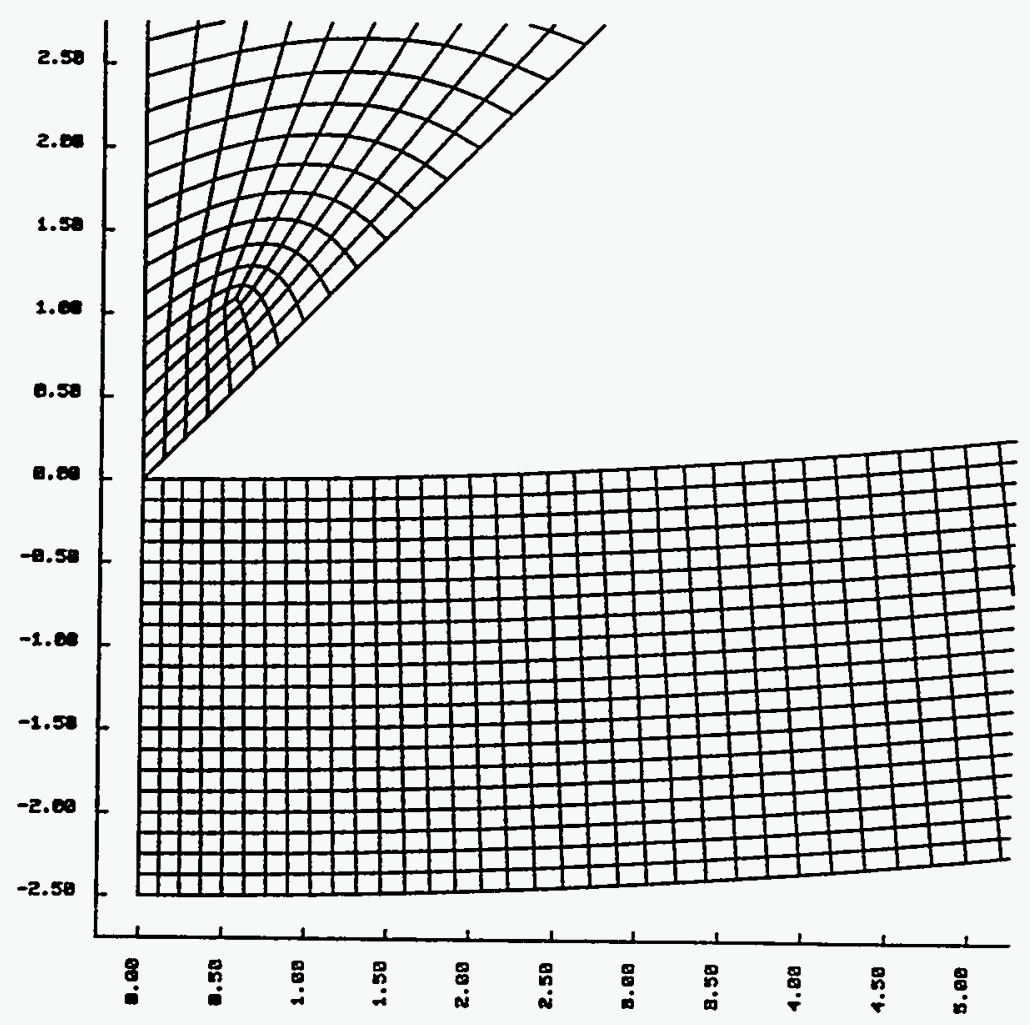

(b) Close-up view.

Figure 2: One slice through the undeformed axisymmetric mesh of the sharp penetrator and safety vessel. 


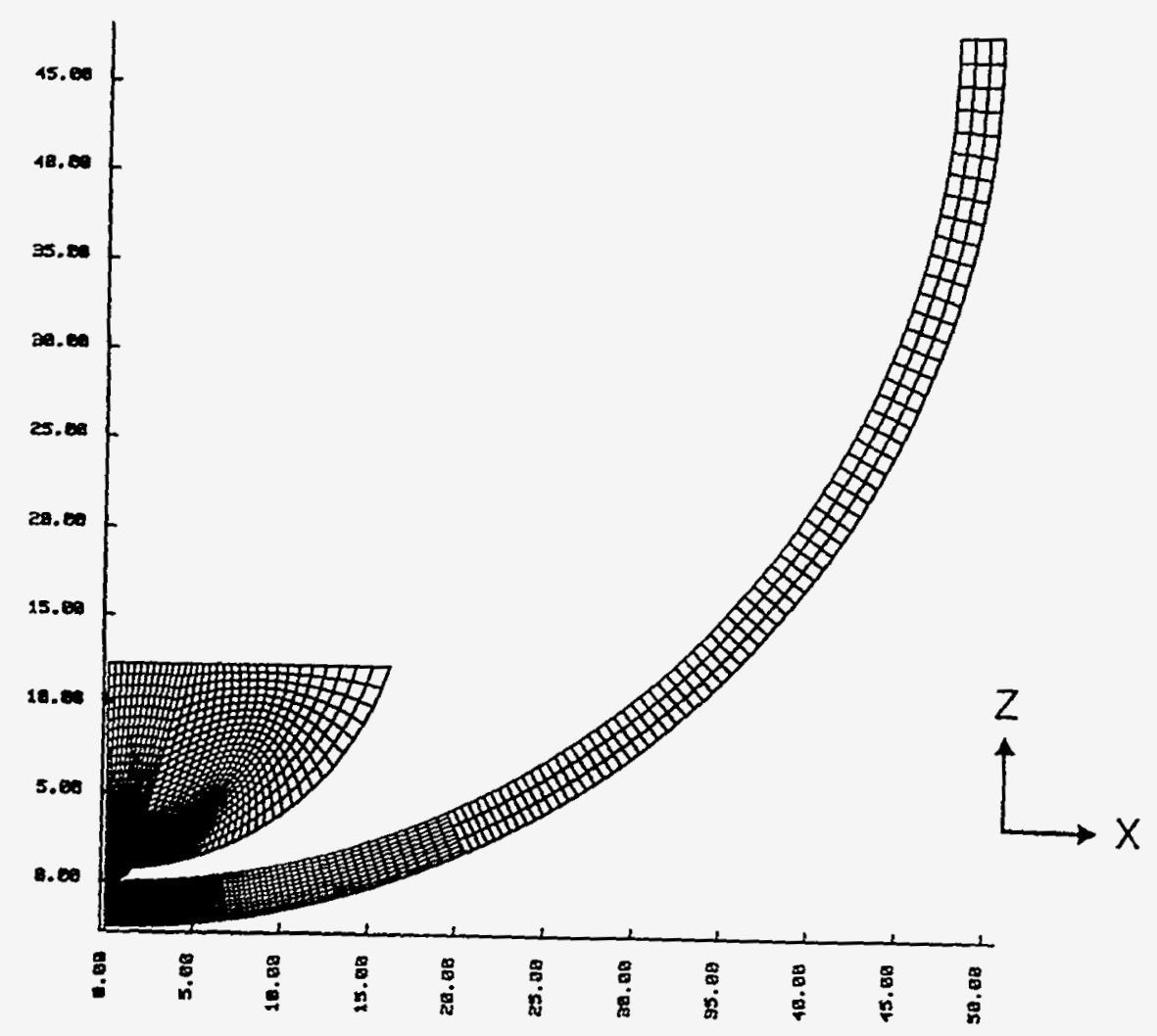

(a) Full view.

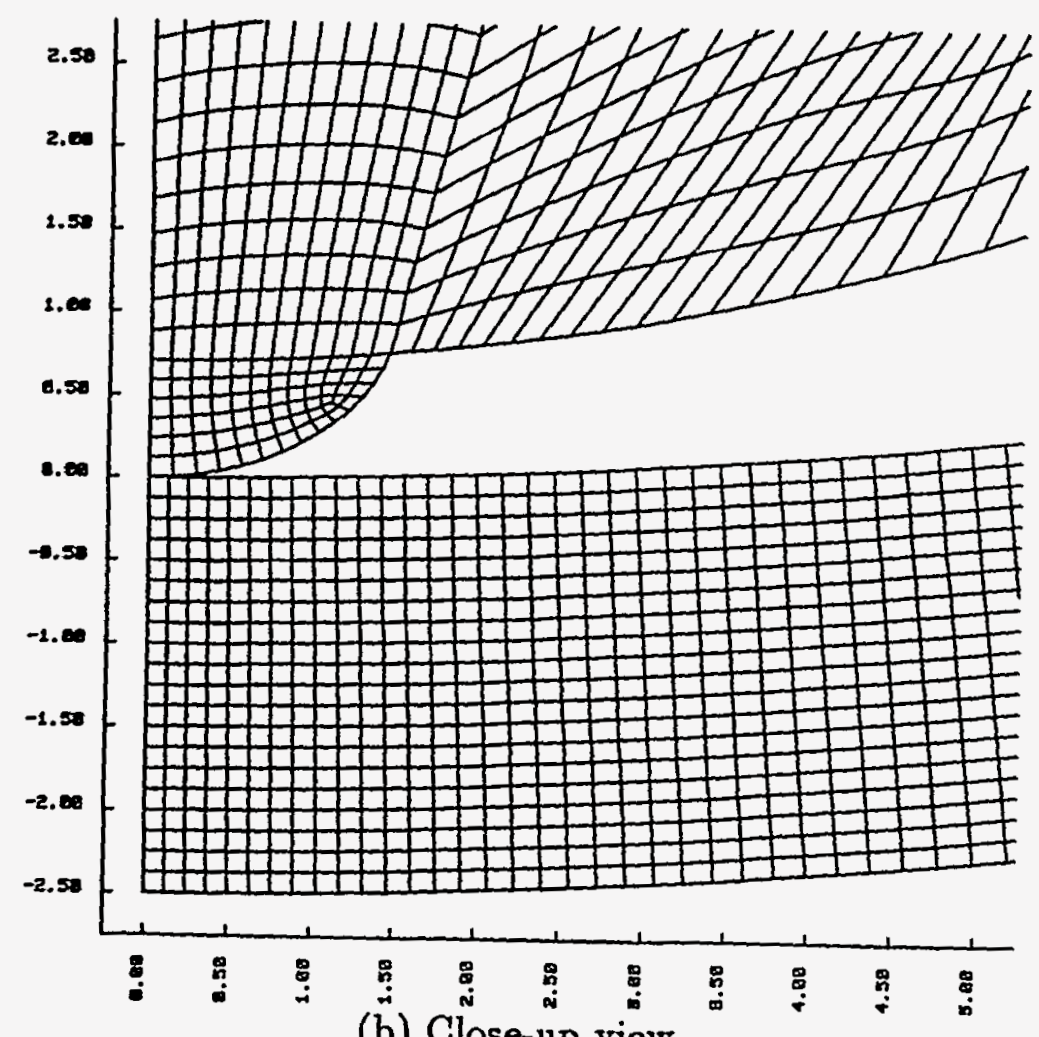

(b) Close-up view. Figure 3: One slice through the undeformed axisymmetric mesh of the blunt pene-
trator and safety vessel. 
Table 1: Initial conditions and chamber geometry used in the gas dynamics analysis.

\begin{tabular}{|l|c|c|}
\hline & Chamber 1 & Chamber 2 \\
\hline \hline $\mathrm{V}\left(\mathrm{in}^{3}\right)$ & 195,432 & 210,732 \\
$\mathrm{P}(\mathrm{psi})$ & 1667 & 14.7 \\
$\rho\left(\mathrm{lb} / \mathrm{in}^{3}\right)$ & $2.05 \mathrm{e}-04$ & $4.17 \mathrm{e}-05$ \\
$\gamma$ & 1.4 & 1.4 \\
\hline
\end{tabular}

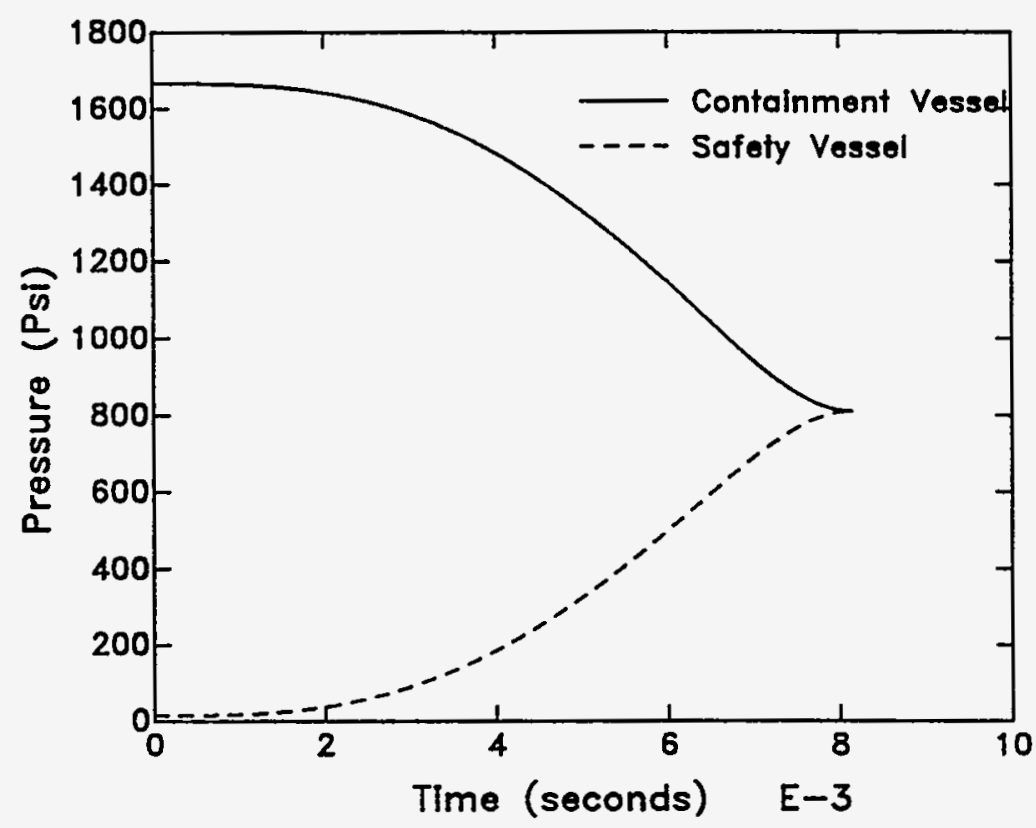

Figure 4: Pressure histories in the confinement and safety vessels. 


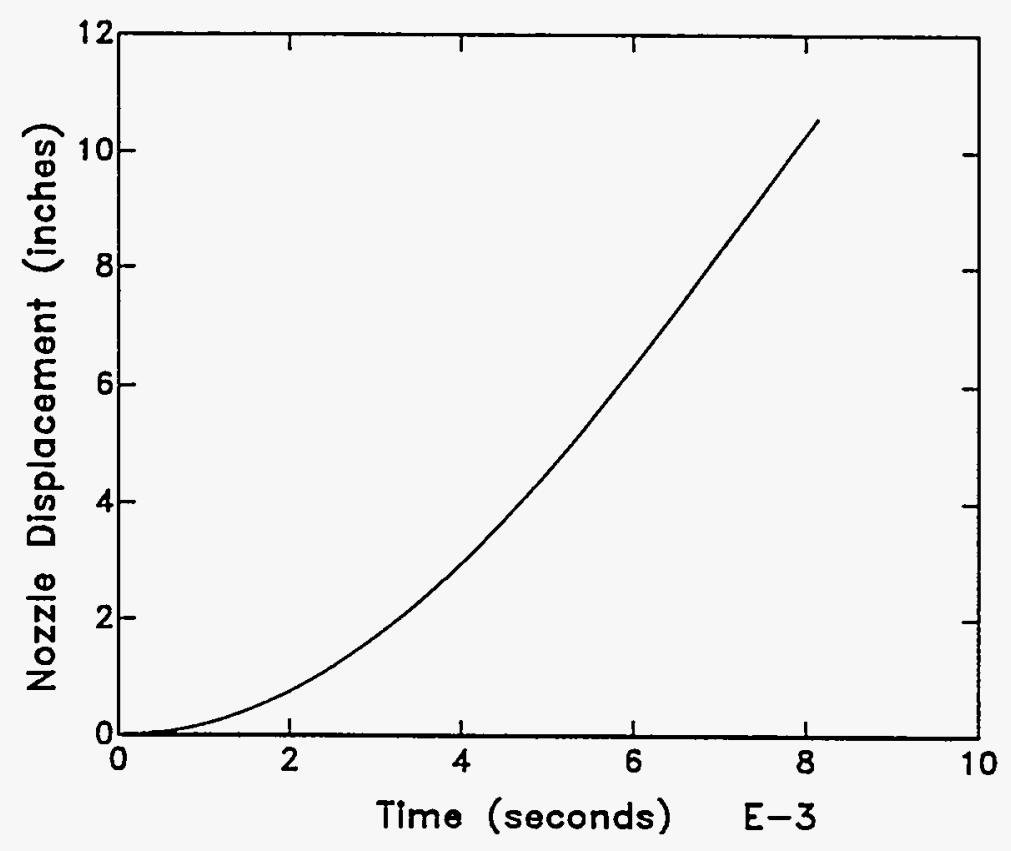

Figure 5: Nozzle displacement history.

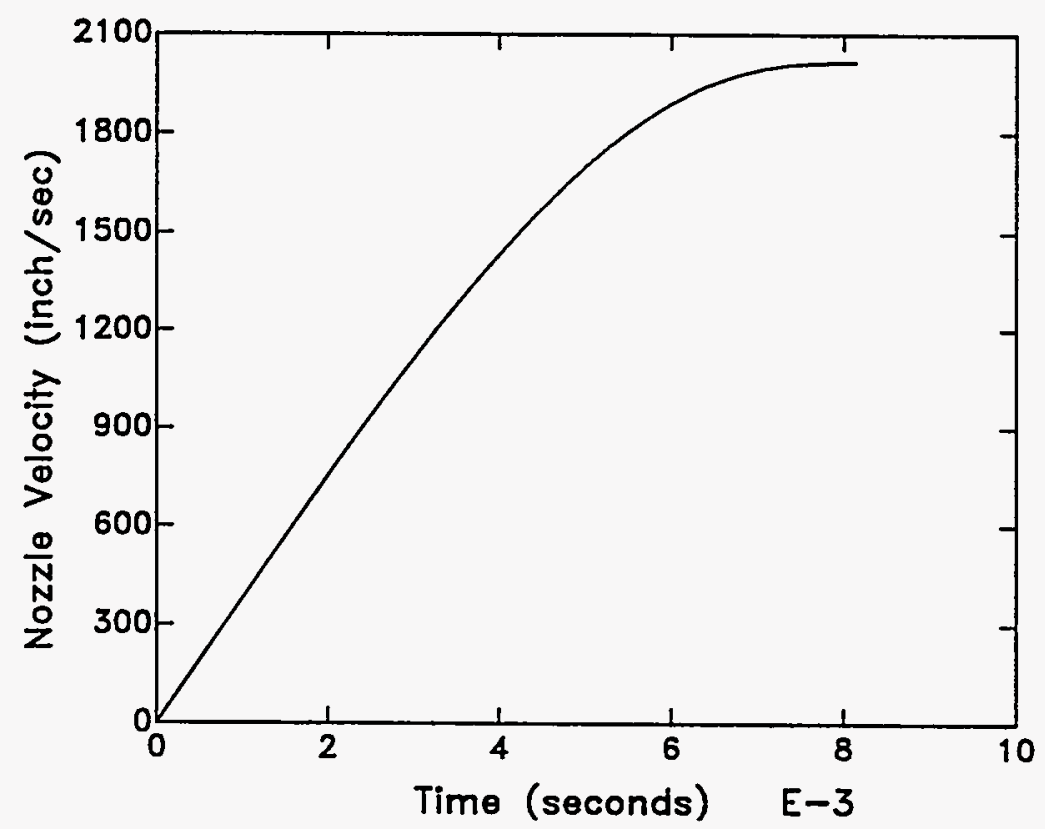

Figure 6: Nozzle velocity history. 
pressure has nearly equalized. Thus we choose to apply an initial velocity of 2015 in/s to the penetrator.

We also performed an inhouse literature search using the DIALOG database to assess possible penetrator velocities. The six journal articles listed in References [2] through [7] were ordered. We reviewed these articles but the information was either insufficient or gave higher estimates for the initial velocity of the penetrator.

\subsection{Material Properties and Ale Parameters.}

Material properties used in the penetration analyses are a Youngs modulus of 29,000 ksi and a Poissons ratio of 0.3 for both the safety vessel and the nozzle. We used yield strengths of $90 \mathrm{ksi}$ for the safety vessel and $150 \mathrm{ksi}$ for steel penetrator. The safety vessel is made of SA 537 steel with a quasi-static strength of $60 \mathrm{ksi}$. The value of $90 \mathrm{ksi}$ reflects our estimate of the strain rate enhanced strength. The nozzle is make of HSLA 100 steel with a quasi-static strength of $120 \mathrm{ksi}$ The value of $150 \mathrm{ksi}$ also reflects our estimate of the strain rate enhanced strength. Both the penetrator and safety vessel were modeled as elastic-perfectly plastic ${ }^{1}$ materials.

We used the ALE formulation on the safety vessel mesh in the vicinity of the penetrator. ALE remaps a distorted mesh to a more regular mesh without user intervention, as shown in Figure 7. Two criteria were applied every 10 time steps to determine if remapping was warranted; these criteria are the minimum area and angle criteria, as shown in Figure 8. We used minimum area and angle criteria of $80 \%$ and 70 degrees, respectively. The minimum area criteria compares the areas of the elements surrounding a node. A node is remapped if the minimum area of any one of the surrounding elements is less than $80 \%$ of the maximum area of any other surrounding element. The minimum angle, or shear distortion criteria compares the angles formed by the corners of the elements surrounding the node. The node is remapped if the sin of an angle is less than the sin of 70 degrees. Obtuse, as well as acute angles, are tested with this criteria. During the remapping, the connectivity of the mesh remains the same, i.e. all nodes along a boundary remain on the boundary and elements are not deleted or created.

\subsection{Results of the Penetration Analyses}

Penetration analyses were performed with the sharp and blunt penetrators previousiy shown in Figures 2 and 3. The deformation of the safety vessel in the vicinity of the penetrator is shown at three times in Figures 9-10 for the sharp penetrator and in Figures 11-12 for the blunt penetrator. As expected, deeper penetration and larger safety vessel displacements are calculated for the sharp penetrator than for the blunt penetrator.

For the sharp penetrator, the safety vessel wall is thinned from an initial thickness of 2.5 inches to a minimum thickness of about 1 inch in 4.35 msecs. At this time, the velocity of the penetrator has been reduced to zero and the maximum radial

\footnotetext{
${ }^{1}$ The hardening modulus of each material was set equal to one-thousandth of the elastic modulus, so each material is essentially perfectly plastic.
} 


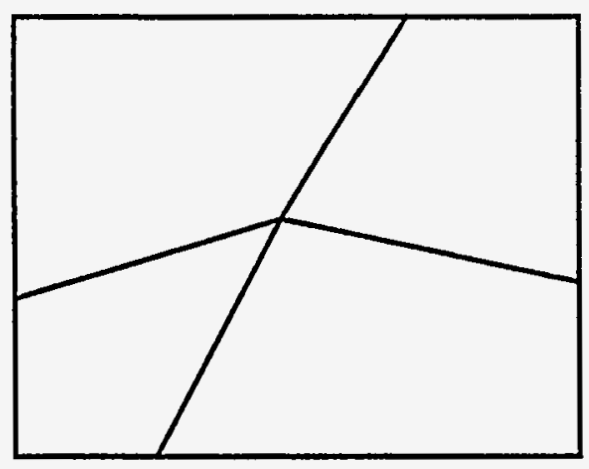

Distorted Mesh

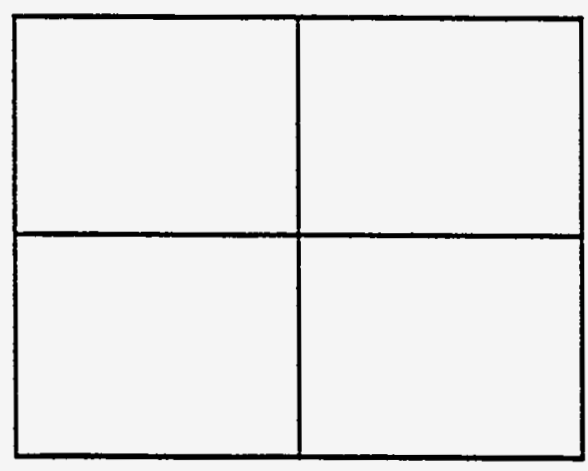

Regular Mesh

Figure 7: Remapping a distorted mesh to a more regular mesh using ALE.

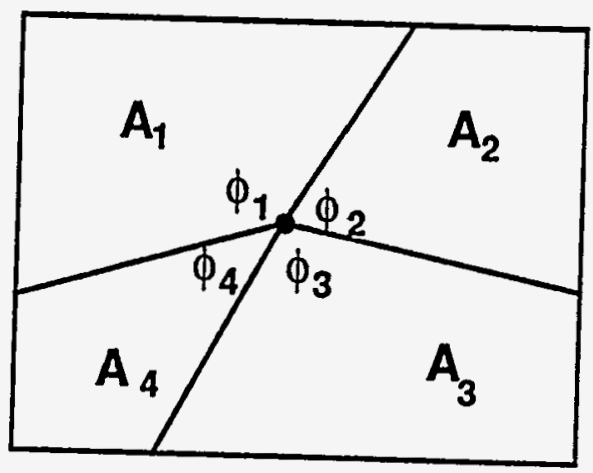

A node is moved if:

$$
\frac{\min \left(A_{1}, A_{2}, A_{3}, A_{4}\right)}{\max \left(A_{1}, A_{2}, A_{3}, A_{4}\right)} \leq 0.8
$$

$\min \left(\sin \phi_{1}, \sin \phi_{2}, \sin \phi_{3}, \sin \phi_{4}\right) \leq \sin 70^{\circ}$

Figure 8: Minimum area and angle criteria with ALE. 
displacement of the safety vessel is 5.1 inches. For the blunt penetrator, the safety vessel wall is thinned to a minimum thickness of about 2 inches in 2.4 msecs. At this time, the velocity of the penetrator is zero and the maximum radial displacement of the safety vessel is 3.0 inches.

Full views of the deformed mesh are given in Figure 13 at times when the radial displacement of the safety vessel wall has reached a maximum. Note that the predicted deformation of the safety vessel is localized in the vicinity of the penetrator, especially for the sharp penetrator.

Contours of maximum principal strain in the safety vessel are shown at 4.35 msecs in Figure 14a for the sharp penetrator and at 2.4 msecs in Figure 14b for the blunt penetrator. These are the times that the velocity of the penetrator has been reduced to zero. These are also the times that the calculated strain in the safety vessel has reached an overall maximum. Note that large strains are predicted in each calculation. For the sharp and blunt penetrators, the maximum principal strains in the safety vessel are $96 \%$ and $36 \%$, respectively.

Available test data ${ }^{2}$ for the safety vessel steel indicates an ultimate elongation of about $30 \%$. The maximum principal strain calculated for both the sharp and blunt penetrators is greater than the measured ultimate strain. For the sharp penetrator, large strains of at least $79 \%$ extend through the thickness of the safety vessel, suggesting complete fracture of the safety vessel wall. For the blunt penetrator, strains greater than $30 \%$ are predicted near the point of impact with the penetrator while smaller strains of about $18 \%$ are predicted through the thickness of the safety vessel wall. This suggests that cracks would initiate near the point of impact. We don't know if they would extend through the thickness of the safety vessel wall without further analyses.

\footnotetext{
${ }^{2}$ Personal communication between N. Borch of Los Alamos National Laboratory and B. Lewis of APTEK, Inc.
} 


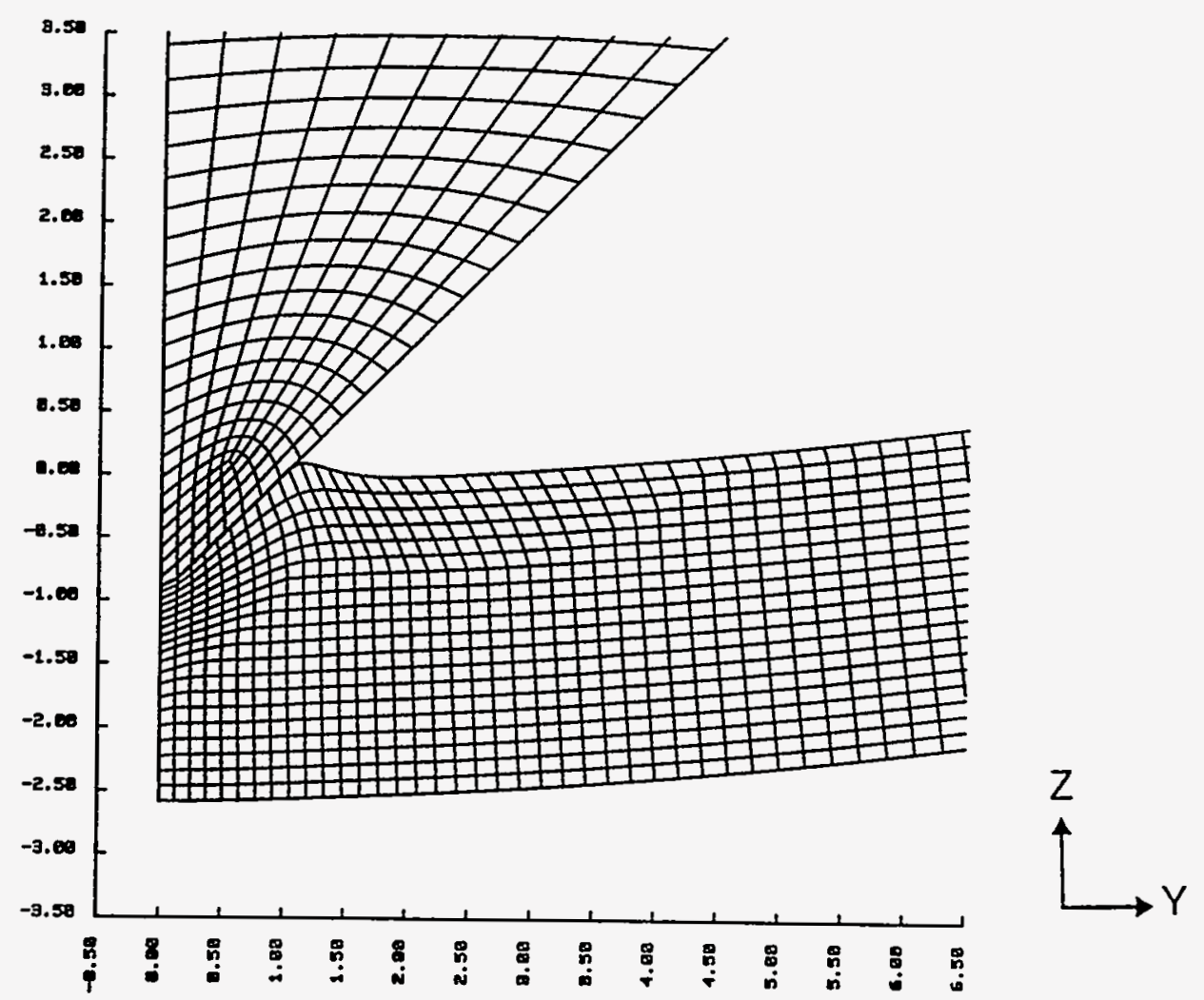

(a) 0.5 msecs.

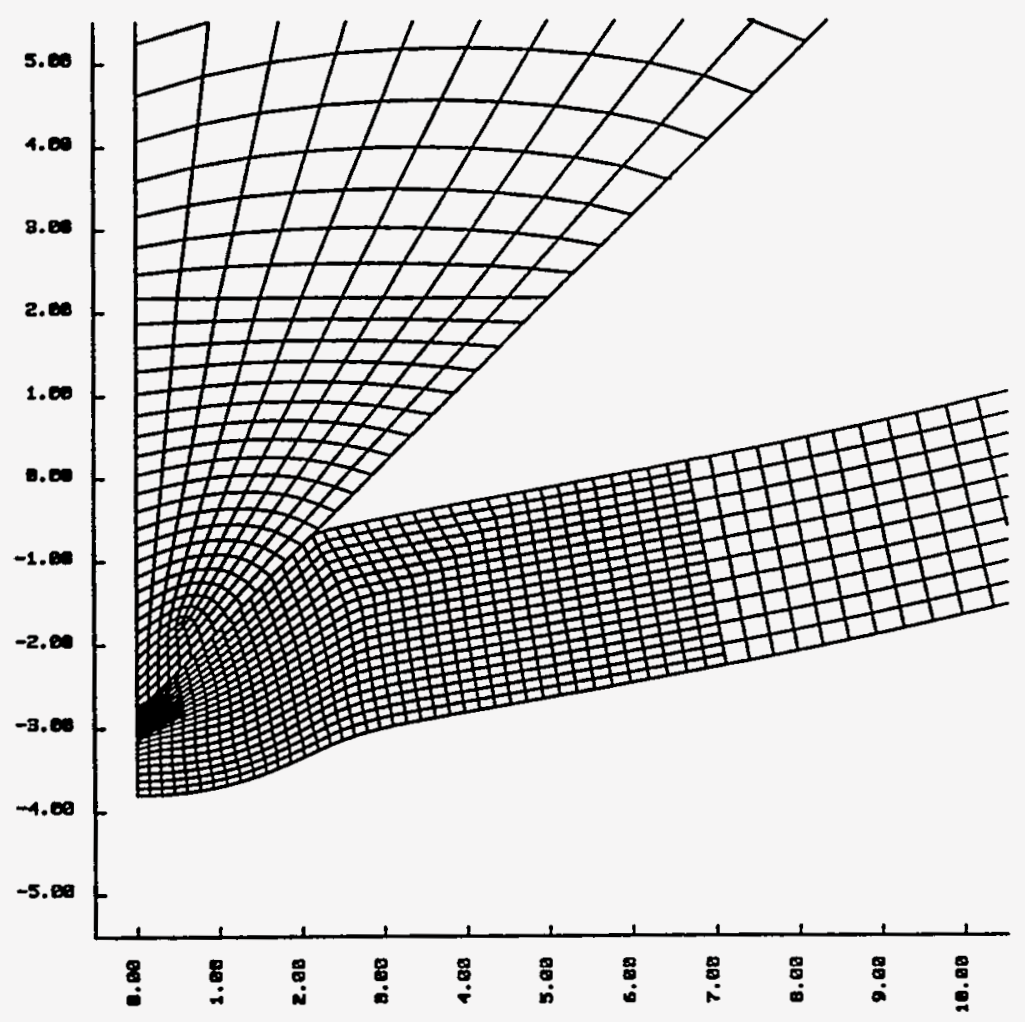

(b) 1.5 msecs.

Figure 9: Deformed mesh of sharp penetrator and safety vessel prior to peak displacment. 


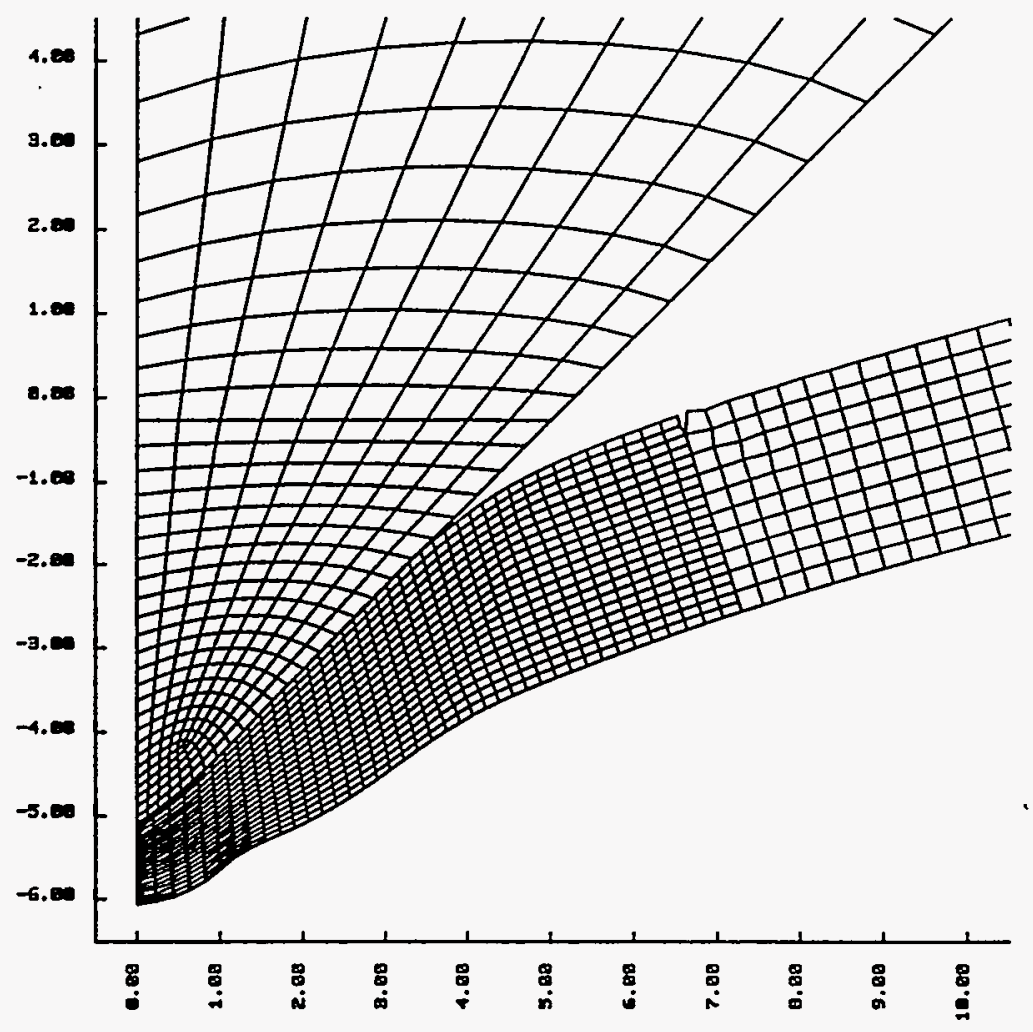

Figure 10: Deformed mesh of sharp penetrator and safety vessel at time of peak displacement (4.35 msecs). 


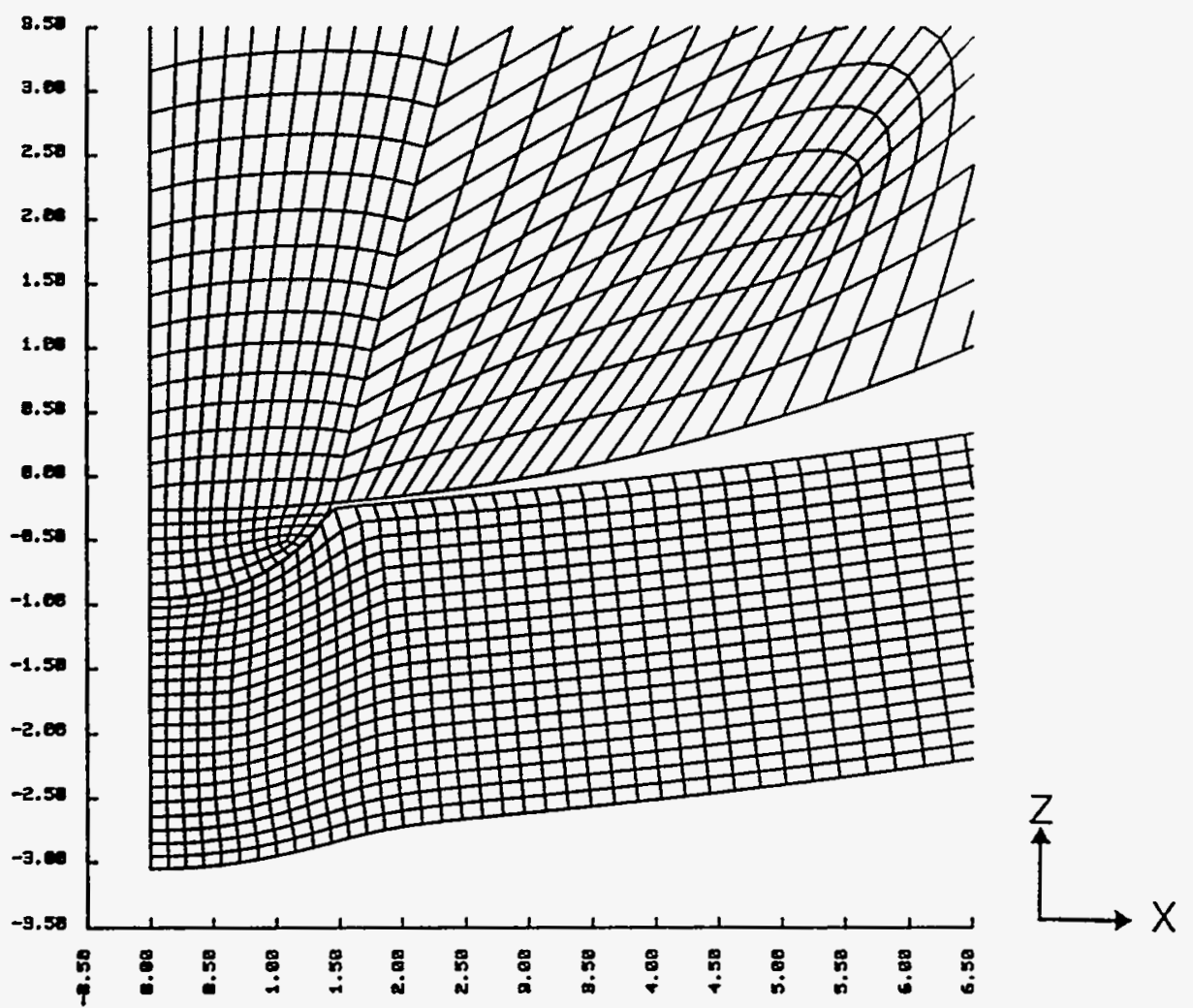

(a) 0.5 msecs.

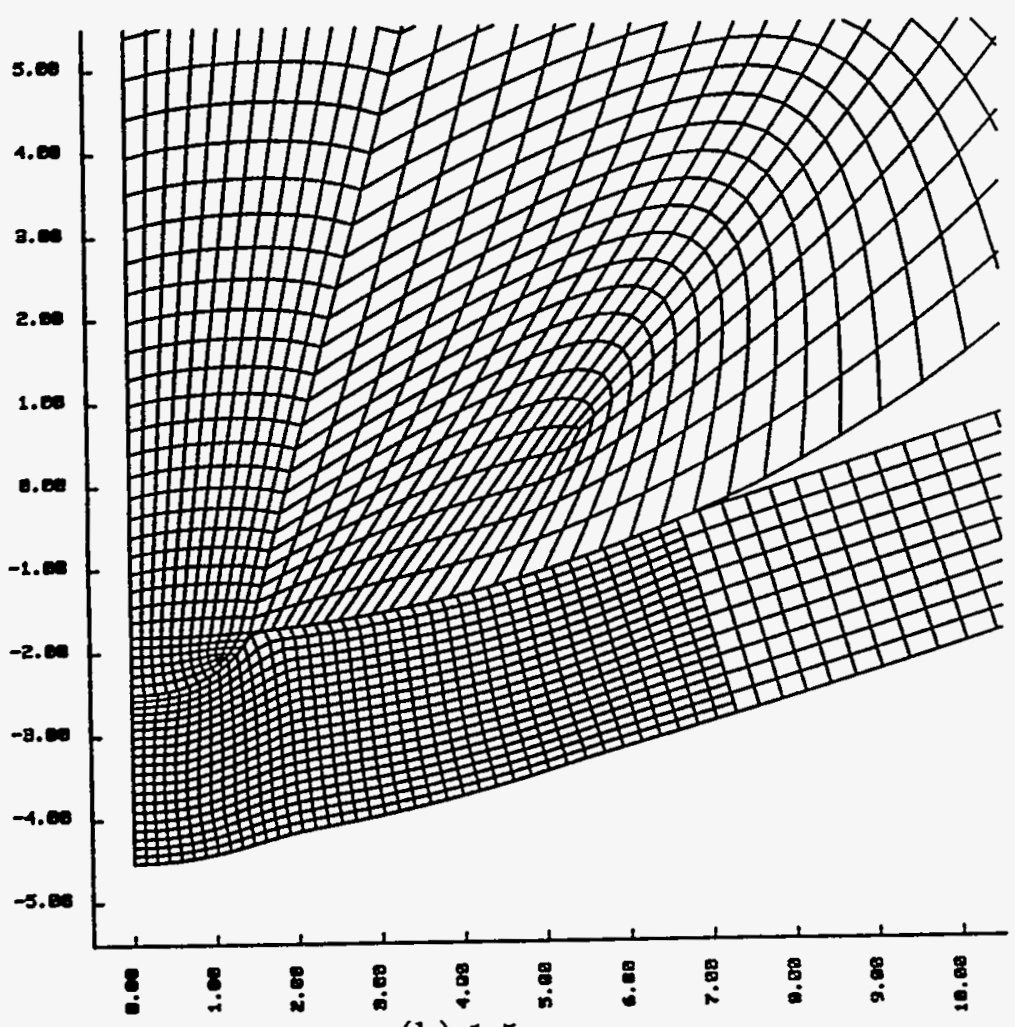

(b) 1.5 msecs.

Figure 11: Deformed mesh of blunt penetrator and safety vessel prior to peak displacment. 


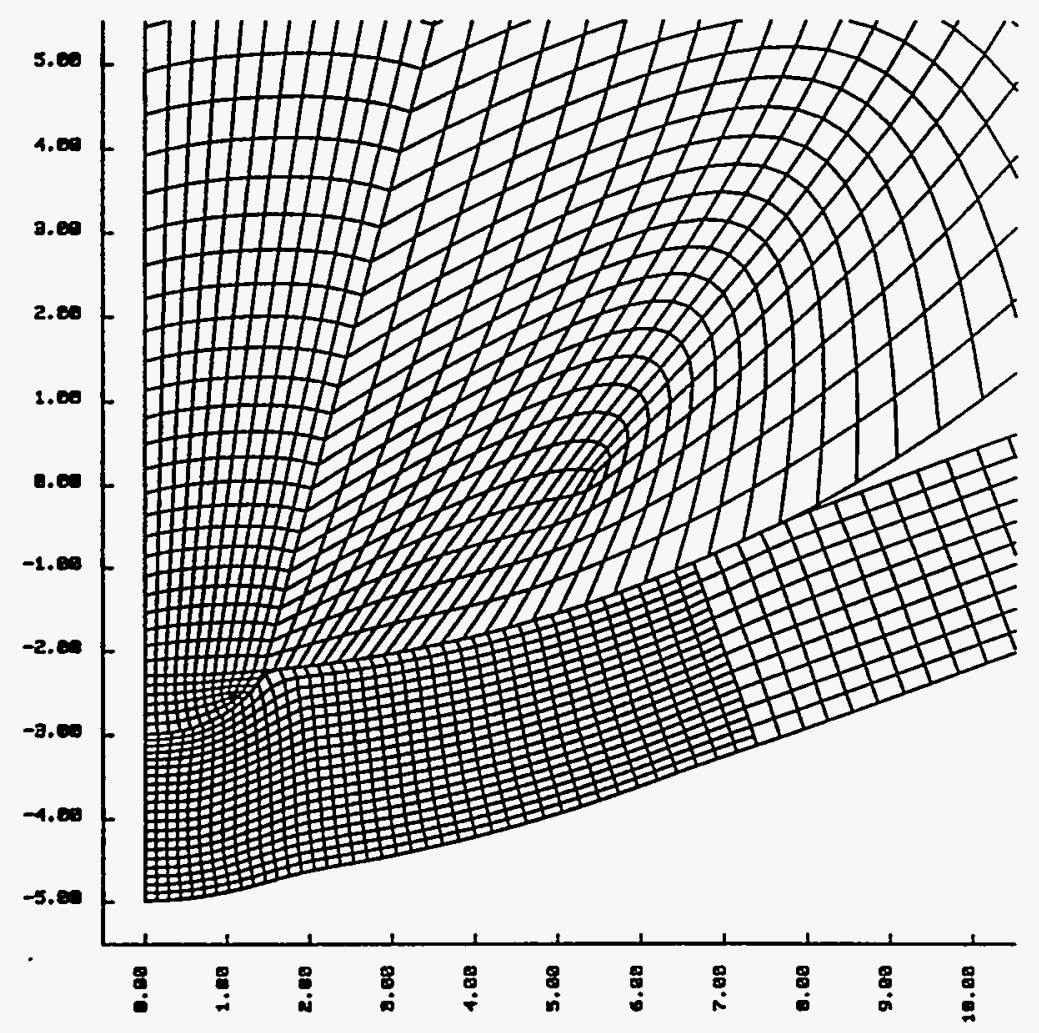

Figure 12: Deformed mesh of blunt penetrator and safety vessel at time of peak displacement (2.4 msecs). 


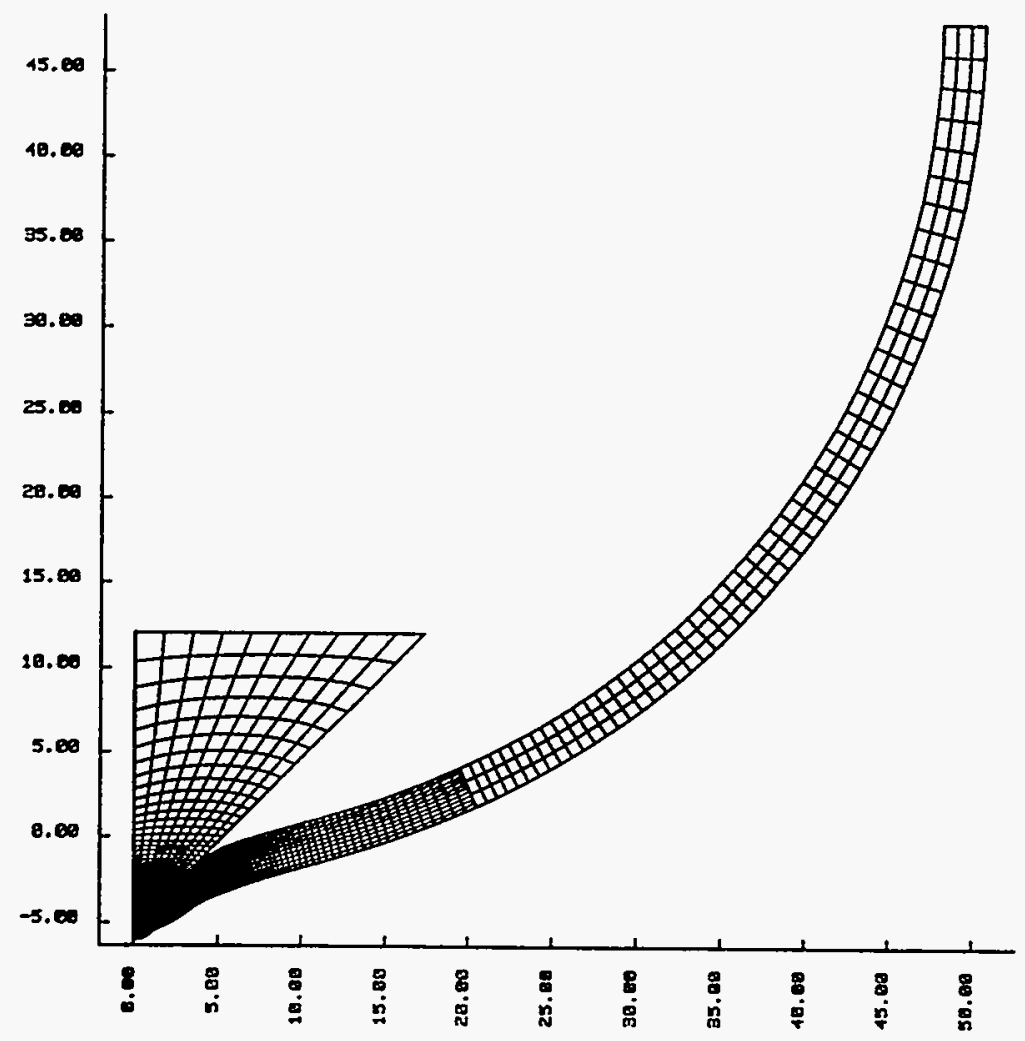

(a) Sharp penetrator at 4.35 msecs.

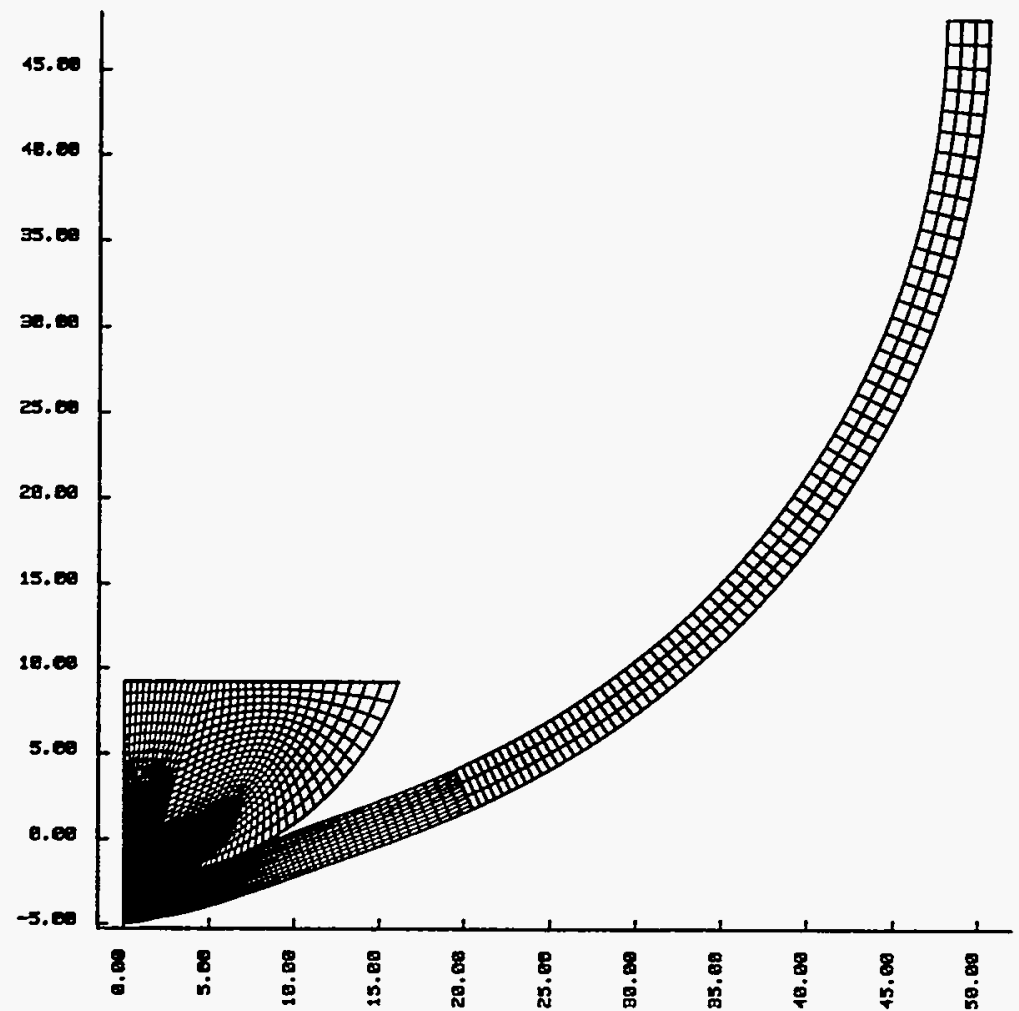

(b) Blunt penetrator at 2.4 msecs.

Figure 13: Full views of deformed mesh showing the maximum radial displacement of the safety vessel wall. 


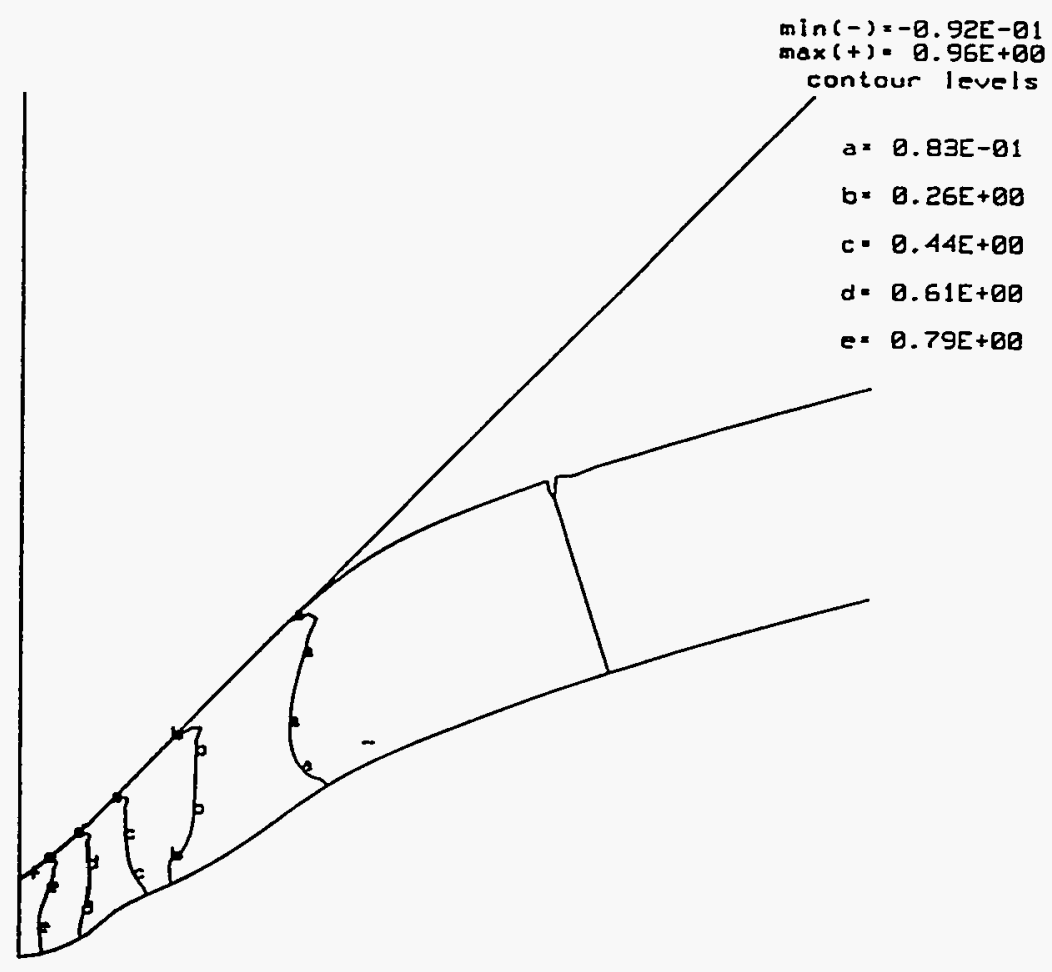

(a) Sharp penetrator at 4.35 msecs.

$\min (-)=0.40 E-03$

$\max (+)=0.36 E+a B$ contour levels

$a=0.61 \mathrm{E}-01$

$b=0.12 E+\theta 0$

c. $0.18 E+\theta 0$

$d=0.24 E+8 B$

$c=0.39 E+08$

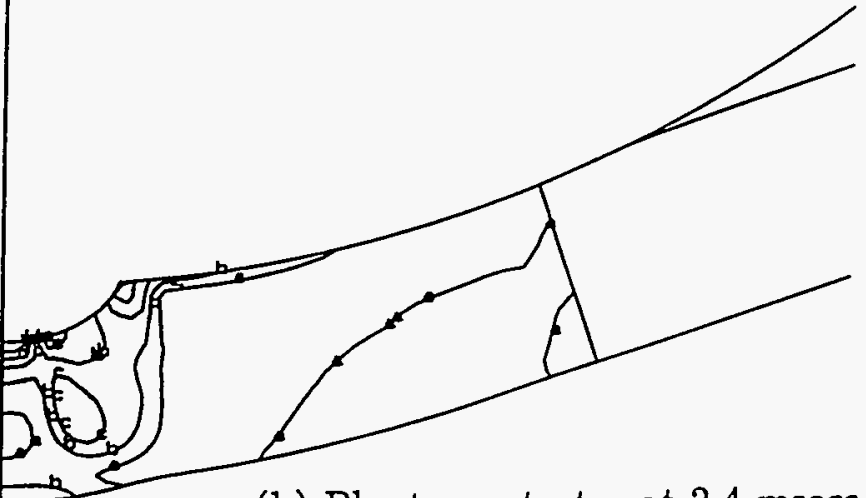

(b) Blunt penetrator at 2.4 msecs.

Figure 14: Contours of maximum principal strain in the safety vessel. 


\subsection{Summary}

The sharp and blunt penetrator analyses were intended to provide upper and lower bounds on the predicted response. The bounds indicated by these simple axisymmetric analyses are those of complete through-the-thickness fracture to partial fracture beneath the tip of the penetrator. Since the actual three-dimensional bolt and nozzle assembly is sharper than the blunt penetrator model, these calculations indicate possible failure of the safety vessel by impact of the bolt head and nozzle assembly.

Our approach was to start with conservative analyses and work from there as results of the analyses indicated. We performed axisymmetric analyses to take advantage of the ALE formulation in DYNA2D. However, not all aspects of the axisymmetric analyses are conservative, as discussed in the following paragraphs.

The most conservative aspect of the axisymmetric analyses is that the center of mass of the nozzle is modeled in-line with the vertical velocity of the nozzle. However, the side view of the nozzle impacting the safety vessel previously shown in Figure 1a suggests that the center of mass is offset from the vertical line of impact, effectively reducing the mass in-line with the velocity. In fact, a more likely impact scenario is that the weld line around the nozzle 'unzips', causing the nozzle to rotate before impact. In such a case, the impact angle could be less than $45^{\circ}$, further offsetting the center of mass from the line of impact. Although an offset center of mass can not be modeled in axisymmetric analyses, it can be modeled in plane strain or three dimensions.

To study the effect of the offset center of mass, we recommend performing DYNA2D plane strain analyses with rotational impact. These analyses should be performed with and without ALE, to determine if penetration can be accurately calculated without the use of ALE. If so, then DYNA3D analyses could be performed (without ALE) with a realistically shaped penetrator model, rather than the sharp and blunt penetrator models used in the DYNA2D analyses.

Another conservative assumption is that we did not take into account the energy required to fracture the weld line around the nozzle. If we had, the initial kinetic energy of the penetrator would be reduced by the fracture energy of the weld. A rough but high estimate for the fracture energy of a 0.5 -inch weld line is that it is equal to $25 \%$ of the initial kinetic energy of the penetrator.

Two aspects of the analyses were unconservative, namely, we did not include pressurization or progressive damage of the safety vessel. Although we predicted that the safety vessel would pressurize to $810 \mathrm{psi}$ in $8.5 \mathrm{msecs}$ from the gas dynamics analysis, we did not apply this pressure history to the safety vessel during the finite element calculation. Standard formulas for static pressurization of a spherical vessel indicate that the safety vessel would be preloaded to $8 \mathrm{ksi}$ (inplane) prior to nozzle impact. In addition, we did not include progressive damage in the analyses, in which the strength of the steel is degraded once a suitable failure criteria is exceeded. Instead we modeled the response of the safety vessel as elastic-perfectly plastic. Any further analyses should include the effects of pressurization and progressive damage on the calculated response. These effects can be included in both two and three dimensional calculations. 


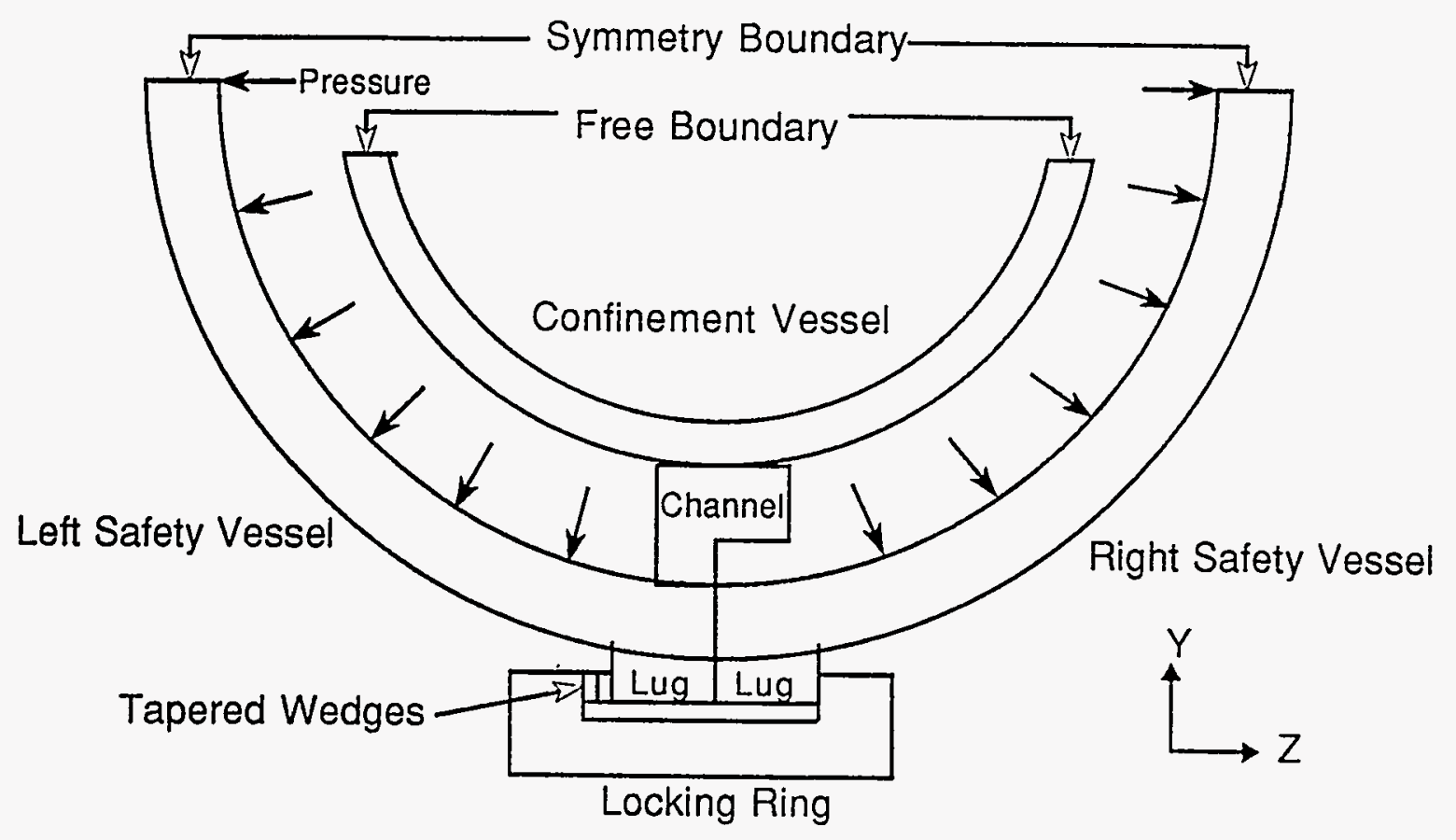

Figure 15: Schematic of the safety vessel closure impact scenario.

\section{Confinement Vessel Impact Analysis}

Finite element analyses were performed to determine the containment capability of the safety vessel closure should catastrophic failure of the confinement vessel occur. If the confinement vessel fails, expanding gas from the explosive detonations products pressurizes the inside of the safety vessel, and accelerates pieces of the fractured confinement vessel until they impact the safety vessel. The case which represents the maximum work done by the gas on the confinement vessel is impact by a half (hemisphere) a confinement vessel. This is the case analyzed in this section.

The closure mechanism is a hydraulically controlled locking ring positioned around the outer circumference the safety vessel. The closure mechanism is supposed to keep the o-ring compressed between the two hemispheres of the safety vessel so that explosive detonation products which escape from the failed confinement vessel don't leak into the atmosphere. The impact scenario is schematically shown in Figure 15. Expanding gas from the explosive charge pressurizes the inside of the safety vessel and the channel protecting the safety vessel closure. The confinement vessel impacts the protective channel with a velocity directed in the minus y-direction. We want to determine how large a gap forms between the two halves of the safety vessel during pressurization and subsequent impact.

We begin this section with a detailed description of the mesh, geometry, and material properties used in the analysis. This is followed by a brief description of the pressure history applied to the safety vessel and the initial velocity of the impacting hemisphere. We also provide an estimate of the preload stress between the two halves of the safety vessel, due to tightening of the locking ring mechanism. However, our 


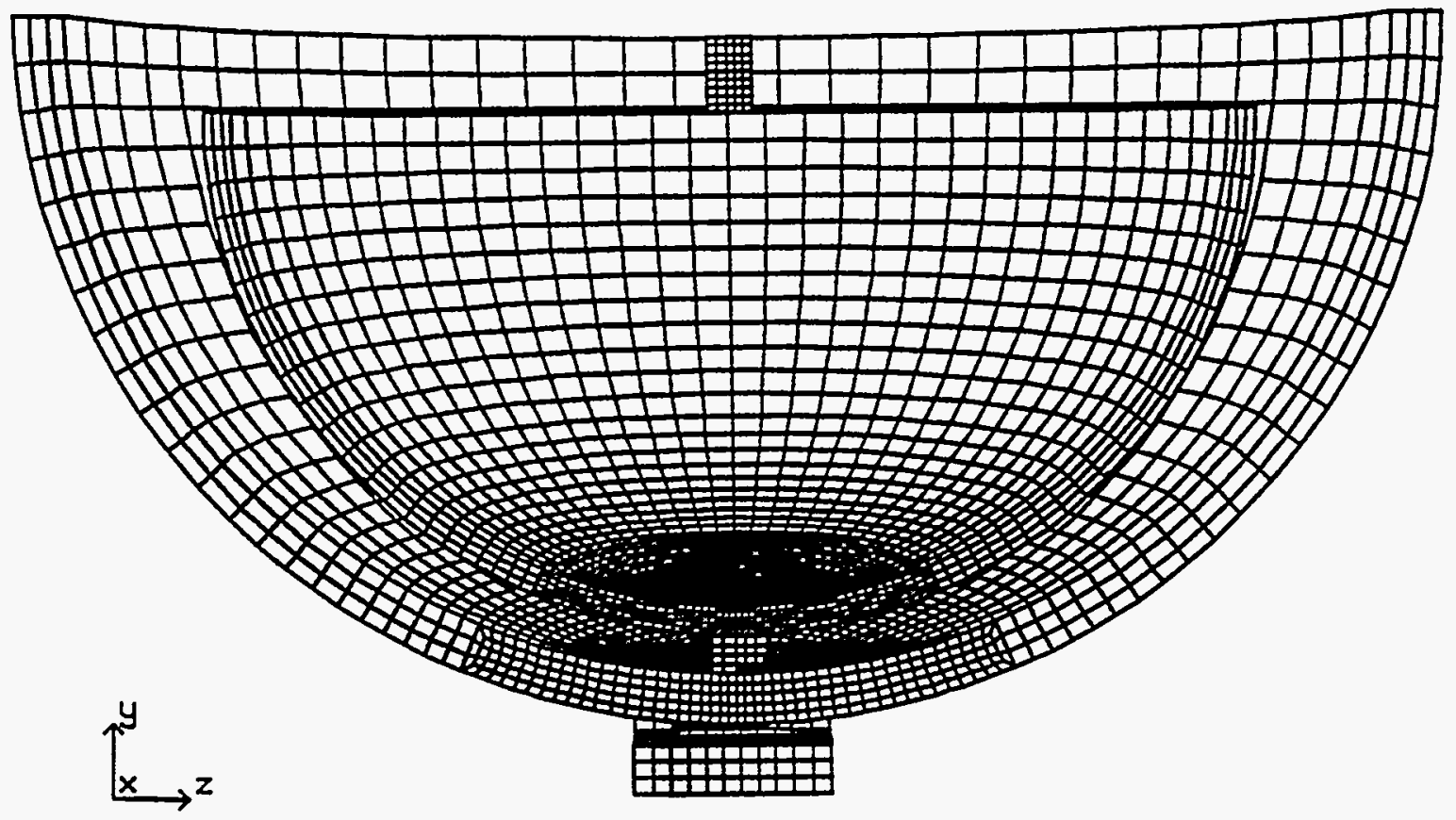

Figure 16: Full finite element mesh.

estimate is so small that no preload was used in the analyses. Finally, deformed configurations are given following impact, showing that the two halves of the safety vessel separate, forming a 0.6 inch gap. We conclude that the locking ring mechanism will not prevent gaseous detonation products from escaping to the atmosphere.

\subsection{Geometry and Mesh}

Front and side views of the finite element mesh used in the analysis are shown in Figures 16 and 17, along with individual views of the various components in Figures 18 through 22. Only one-fourth of the safety vessel, confinement vessel, protective channel, and locking ring are modeled because the geometry and loading conditions are assumed to be quarter-symmetric. Symmetry planes are assumed along one horizontal and one vertical mid-plane. The inner diameter of the safety vessel is 8 feet and the the vessel thickness varies between 2.5 and 3.7 inches. We used a uniform thickness of 3.7 inches in our finite element analysis because this is the measured thickness in the vicinity of the locking ring mechanism. A sliding-with-voids interface is modeled between the two halves (hemispheres) of the safety vessel. We will refer to these two halves as the right and left halves. The sliding-with-voids interface allows separation between the right and left halves of the safety vessel, but prevents penetration.

The inner diameter of the confinement vessel is 6 feet and the wall thickness is 2 inches. A symmetry plane is modeled along the vertical mid-plane. However, no constraint (free surface) is modeled along the horizontal mid-plane, because this surface is assumed to be the fracture plane of the confinement vessel. We also assumed that the point of impact between the confinement vessel and protective channel was a 


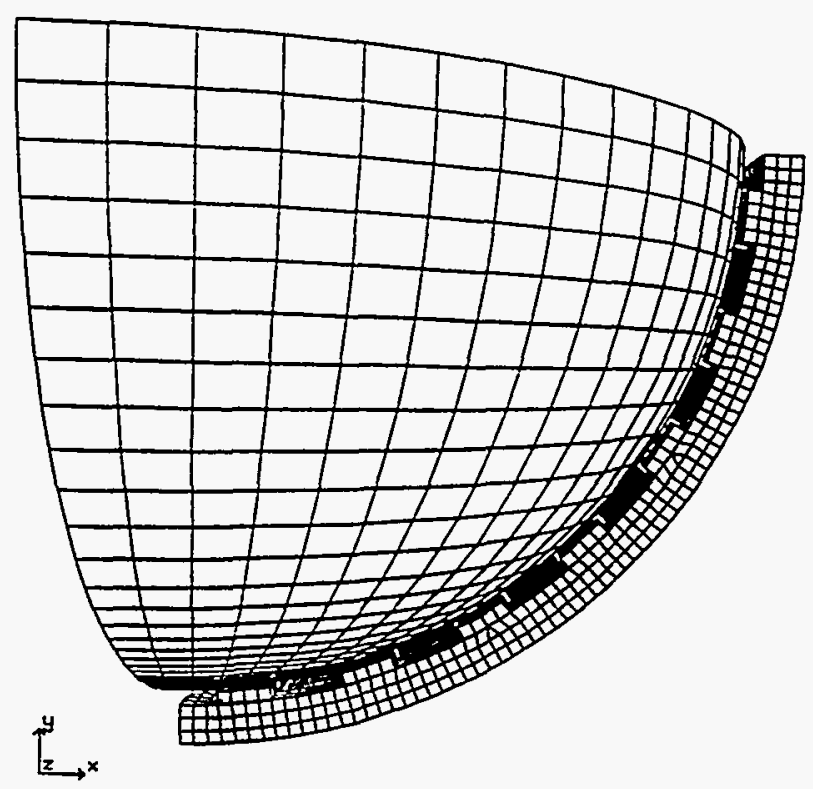

Figure 17: Side view of finite element mesh.

34-inch diameter nozzle on the confinement vessel. The detailed geometry of this nozzle was not explicitly modeled. Instead, we increased the density of the confinement vessel in the vicinity of the nozzle to account for the mass of the nozzle.

The geometry and mesh of the protective channel are shown in Figure 18. The protective channel is welded to the left half of the safety vessel. A close-up view of the positioning of the channel on the left safety vessel is shown in Figure 19. The channel and left vessel have differing mesh refinements, so a tied interface is modeled between the two parts to join them together. We also modeled a sliding-with-voids interface between the underside of the protective channel and the inner surface of the right vessel. This is because relative sliding between the left and right safety vessels causes the underside of the channel to impact the right safety vessel, as discussed in Section 2.5. We also modeled a sliding-with-voids interface between the upper surface of the channel and outer surface of the confinement vessel. This interface prevents penetration when the protective channel impacts the confinement vessel.

As part of the locking mechanism, twenty-nine pairs of intermittently spaced lugs are welded around the outer circumference of the safety vessel closure. Such an odd number of lugs cannot be modeled exactly with a quarter-symmetric model. Instead, we modeled seven pairs of lugs over one-fourth of the circumference, which is equivalent to 28 pairs around the full circumference. One lug of each pair is welded to the left vessel while the other lug is welded to the right vessel. The placement of the lugs attached to the left and right safety vessels is shown in Figure 20. Sliding-withvoids surfaces are modeled between the left and right lugs to prevent penetration. The lugs on the left safety vessel are 5 inches long in the circumferential direction, 4 inches wide, and 1.25 inches thick. The lugs on the right safety vessel are 5.875 

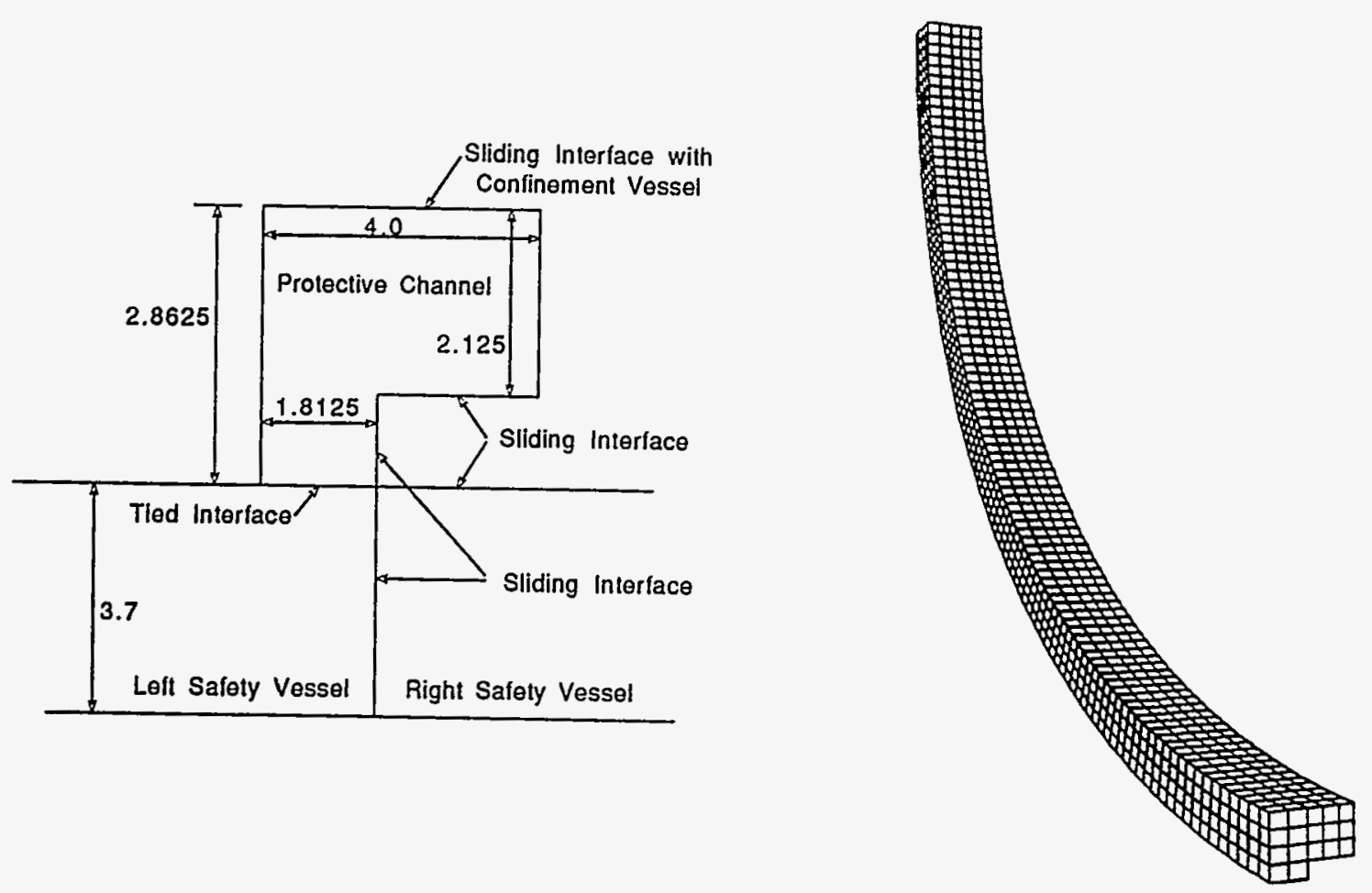

Figure 18: Mesh and geometry of the protective channel.

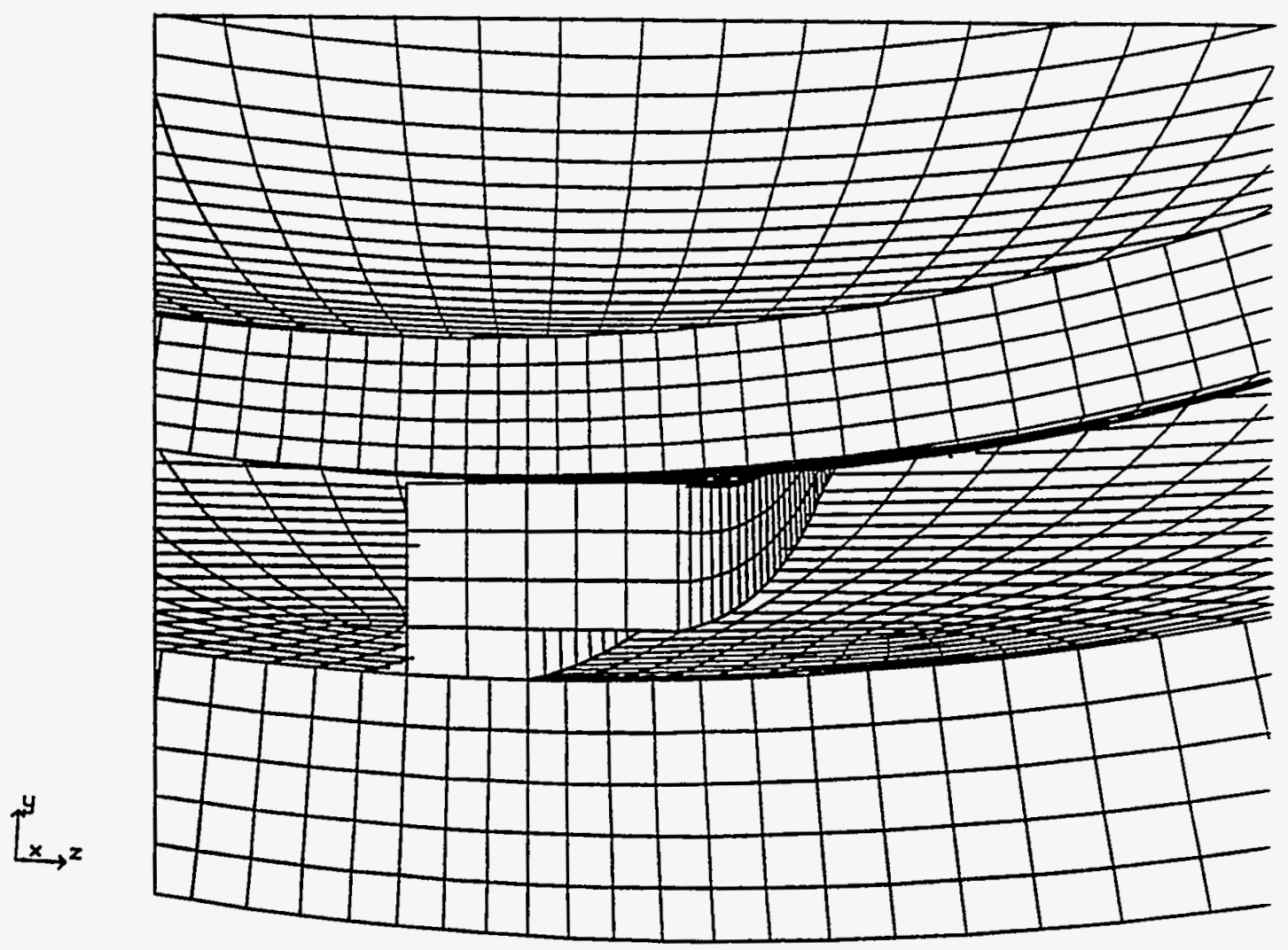

Figure 19: Mesh showing positioning of channel on left safety vessel. 


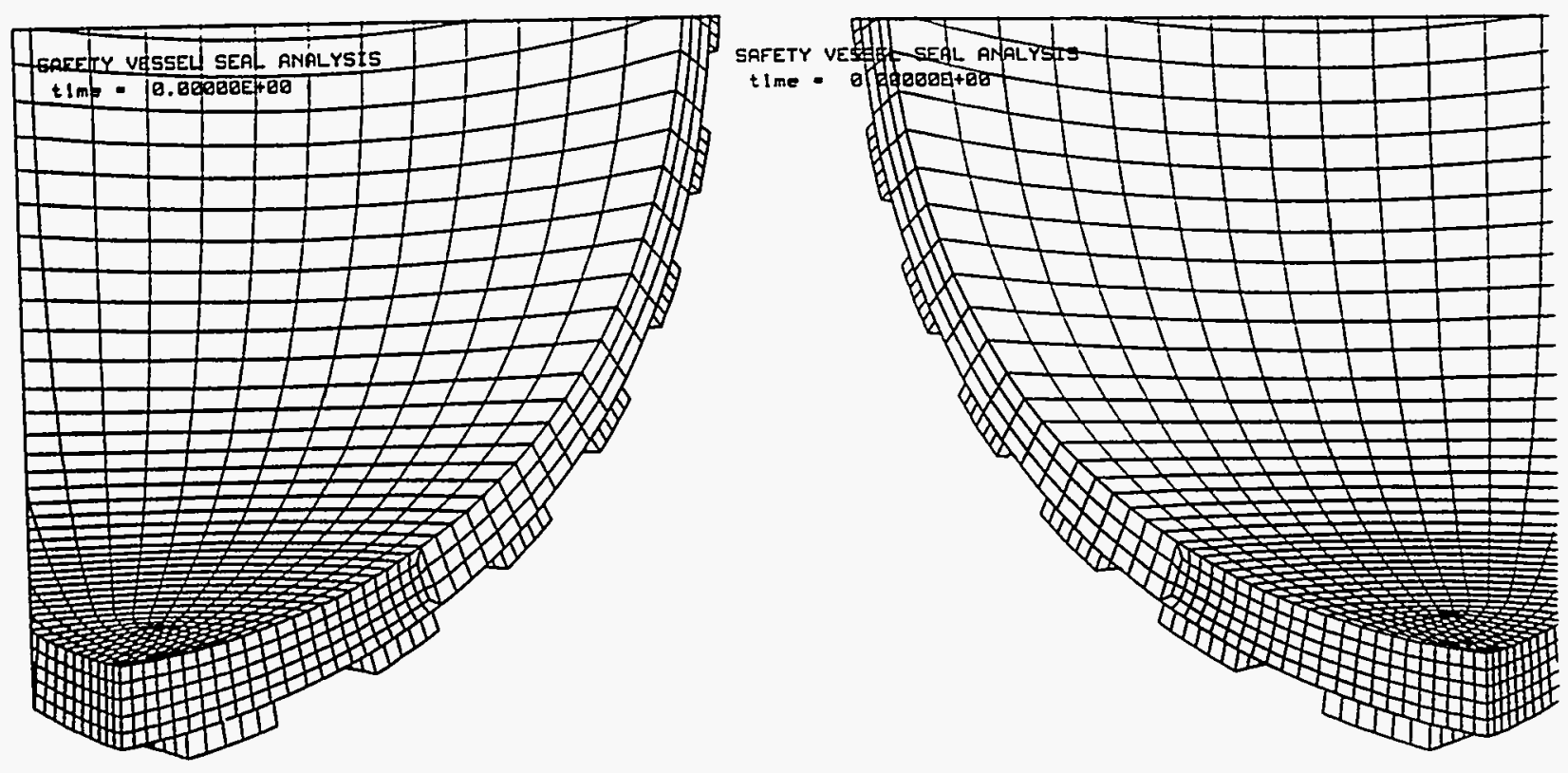

Figure 20: Placement of lugs tied to left and right safety vessels.

inches long in the circumferential direction, 4 inches wide, and 1.25 inches thick.

The locking ring also has twenty-nine paris of intermittently spaced lugs welded to its inner circumference. Again, we modeled only seven pairs of lugs for the quartersymmetric model, as shown in Figure 21. The locking ring is 14.3125 inches wide and 3.625 inches thick, not counting the lugs. The lugs are 4.875 inches long in the circumferential direction, 2.75 inches wide, and 1.25 inches thick.

The geometry of the lugs and wedges used in the analyses was obtained from on-site measurements by personnel at LANL and from drawings by the designer of the locking ring mechanism, Melco Steel. A tapered wedge with a surface area of 3.75 square inches is welded to each lug of the left safety vessel. A tapered wedge with a surface area of 3.5 square inches is welded to each lug on the left side of the locking ring (refer back to Figure 15). When the locking ring is hydraulically tightened, the tapered surfaces of each of these wedges are supposed to align in intimate contact, compressing the o-ring between the two halves of the safety vessel up to $1 / 16$ of an inch. This brings the two surfaces of the left and right safety vessel into intimate contact. LANL measured different tapers for the locking ring and safety vessel wedges, as follows: $2.86^{\circ}$ for the locking ring wedge and $1.91^{\circ}$ degrees for the safety vessel wedge. A view of the taper was not shown in the Melco drawings. However, an engineer at Melco stated ${ }^{3}$ that the locking ring and safety vessel wedges should have the same taper. Hence it is possible that some wear and tear of the wedges has taken place, or accuracy of the on-site measurements was limited.

Two views showing the alignment of the lugs/wedges of the locking ring and safety

\footnotetext{
${ }^{3}$ Telephone conversation with engineer Jeff Cowan at Melco Steel in Azusa, California.
} 


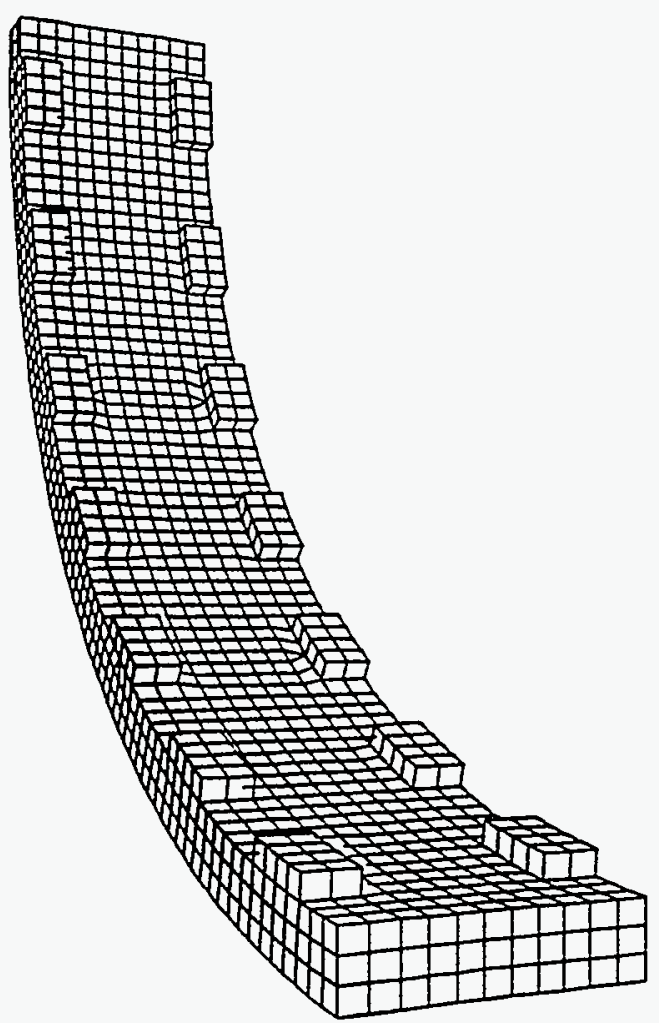

Figure 21: Finite element mesh of the locking ring.

vessel are shown in 22. The safety vessel has been removed for clarity. Numerous sliding-with-voids surfaces are modeled between the wedges, lugs, and locking ring surfaces. We also modeled the locking ring and safety vessel wedges in contact over the entire surface area of 3.5 inches, thus neglecting any effects that partial contact from wear and tear might have on the computational results.

Two possible impact scenarios were considered, namely, impact directly in line with the lugs, and impact in line with the intermittent space between the lugs. We believe that the worst case is represented by impact between the lugs, and this is the case we analyze in this section. This is why space between the lugs, not the lugs themselves, lies on the horizontal symmetry plane in all of the preceeding figures.

All sliding-with-voids surfaces are modeled with a rate-dependent friction model. The coefficient of friction, $\mu$, is given by

$$
\mu=\mu_{k}+\left(\mu_{s}-\mu_{k}\right) \exp ^{-\beta v}
$$

where $\mu_{k}=0.57$ and $\mu_{s}=0.74$ are the kinetic and static coefficients of friction for steel, $\beta=4600 \mathrm{~s} /$ in is a transition coefficient governing the rate of change from static to kinetic friction, and $v$ is the relative velocity between the two sliding surfaces.

\subsection{Material Properties}

All components of the safety vessel analysis are steel. We used a Young's Modulus of 29 million psi and a Poisson's ratio of 0.3. Material response was assumed to be elastic-plastic. We used a plastic tangent modulus of 30 thousand psi (one thousandth of the elastic modulus), so the response is nearly perfectly plastic. 


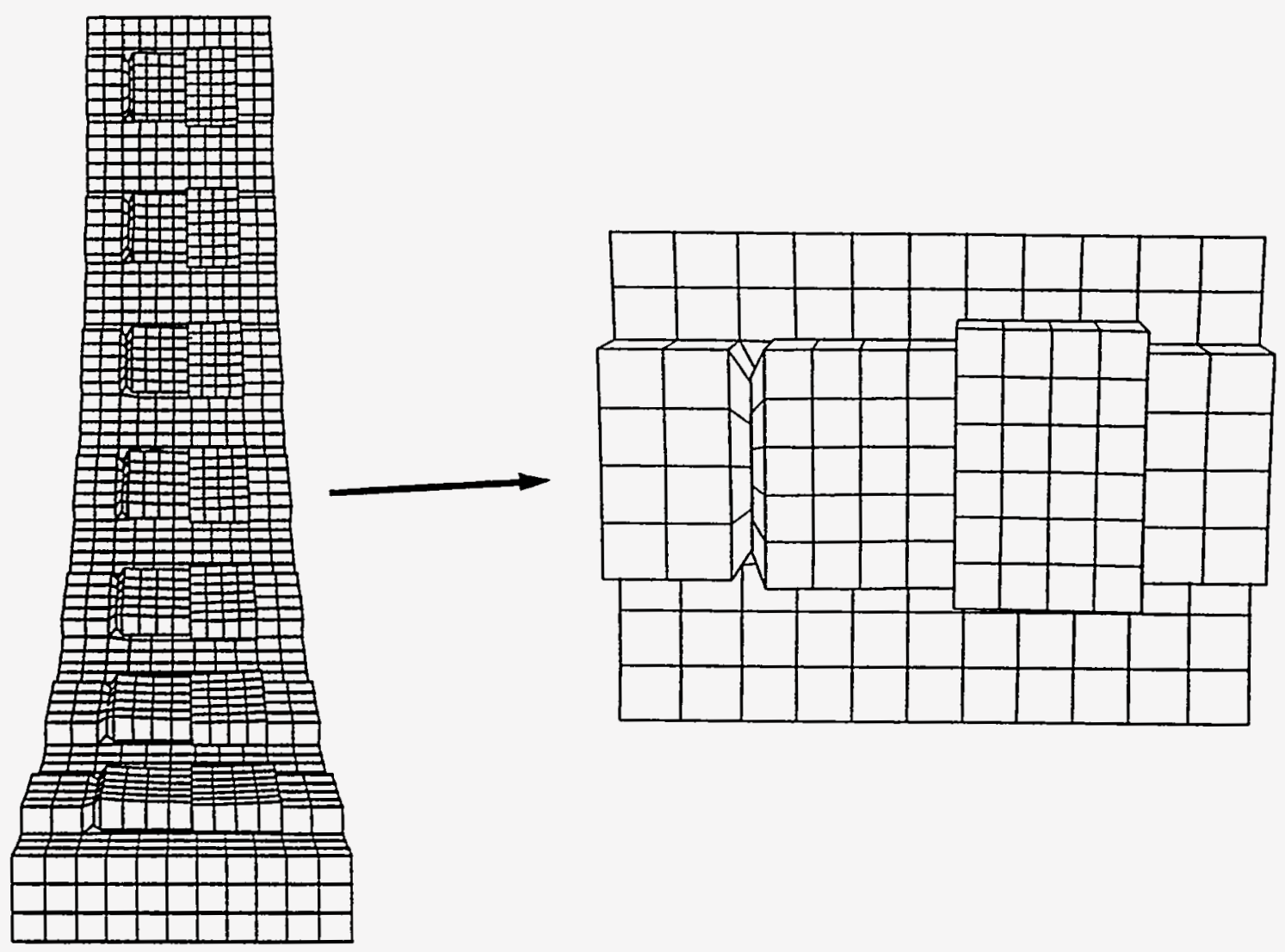

Figure 22: Two views showing alignment of the locking ring and safety vessel lugs/wedges.

The yield strengths of the various steels used in the analyses are listed in Table 2. The yield strength listed for the protective channel is $20 \mathrm{ksi}$ higher than the static value, to account strength enhancement at high strain rate. No other yield strengths were strain rate enhanced.

Yield strengths were provided by LANL and Melco Steel from test measurements or handbook values. In three cases, the strengths provided by Melco were different than those provided by LANL, so we used LANL's values. In two of the three cases, Melco's and LANL's measured strengths agreed within $12 \%$. Melco suggested measured values of $53.8 \mathrm{ksi}$ for SA537-B steel and 82.2 to $88.0 \mathrm{ksi}$ for HY80 steel. LANL recommended measured values of $56.7 \mathrm{ksi}$ for SA537-B steel and $75.9 \mathrm{ksi}$ for HY80 steel. However, Melco's and LANL's yield strengths for carburized AISI 1018 steel differed significantly. An engineer at Melco stated ${ }^{4}$ that compression tests were performed on three wedges to obtain yield strengths ranging from 83 to $112 \mathrm{ksi}$. LANL recommended handbook values ranging between 36 to $50 \mathrm{ksi}$. We used a value of $40 \mathrm{ksi}$ in our analysis.

\subsection{Locking Ring Preload}

We determined that the locking ring mechanism does not significantly preload the safety vessel, if at all. By preload, we mean to compress the two halves of the safety vessel together by hydraulically tightening the locking ring, such that compressive

\footnotetext{
${ }^{4}$ Telephone conversation with engineer Jeff Cowan at Melco steel.
} 
Table 2: Yield strengths used in analyses.

\begin{tabular}{|c|c|c|}
\hline Component & Steel & Yield Strength (ksi) \\
\hline Confinement Vessel & HSLA-100 & 120 \\
Safety Vessel & SA537-2 & 56.7 \\
Safety Vessel Lugs & SA537-1 & 56.7 \\
Protective Channel & SA515-70 & 58 \\
Locking Ring and Lugs & HY80 & 75.9 \\
All Carburized Wedges & AISI 1018 & 40 \\
\hline
\end{tabular}

stresses develop in the safety vessel following compression of the o-ring. The hydraulic mechanism uses two pumps in series at 1000 psi each. The area over which the pump pressure acts is 6.07 square inches. This area is obtained from the 3-inch inner diameter of each pump, minus the area of a 1.125-inch diameter shaft which connects to the locking ring. Thus the pumps apply a total force of 12,149 lbs to the locking ring. This applied force must overcome the frictional forces between the steel wedges/lugs and compress the o-ring, before applying a compressive preload to the two halves of the safety vessel.

There are 29 sets of wedges/lugs around the circumference of the safety vessel, so the applied force per wedge/lug is $419 \mathrm{lbs}$. We estimate the weight of the locking ring to be about $5400 \mathrm{lbs}$, or $186 \mathrm{lbs}$ per wedge/lug. The applied force needed to overcome the frictional force between the wedges is equal to the static coefficient of friction ( $\mu_{k}=0.74$ ) times the weight of the locking ring. This force is 138 lbs per wedge/lug. This leaves $281 \mathrm{lbs}$ of applied force to compress the o-ring and preload the safety vessel closure.

If we neglect the force required to compress the o-ring for simplicity, then the locking ring preload can be roughly estimated from the diagram in Figure 23. If the locking ring lug is turned a vertical distance $\delta x$, then the lug/wedge system wants to expand a horizontal distance equal to $\delta x \tan \theta$, where $\theta=2.4^{\circ}$ is the average taper of the wedges. This taper is greatly exaggerated in Figure 23. If we assume that the locking ring is so stiff that it doesn't expand, then the compressive strain in the lug/wedge system is:

$$
\epsilon=\frac{\delta_{x} \tan \theta}{l}
$$

where $l=7.5676$ inch is the combined width of the lugs and wedges. This strain corresponds to a compressive stress of $\sigma=E \epsilon$. The normal force between the two wedges is $F_{n}=\sigma A$, where $A=3.5$ inches is the contact area between the wedges. An estimate of the applied (frictional) force needed to tighten the locking ring $\delta x$ inches is $F_{f}=\mu F_{n}$, or:

$$
F_{f}=\frac{\mu E A \delta x \tan \theta}{l}
$$

Using this formula, the locking ring turns $\delta_{x}=.00065$ inches in response to an applied 


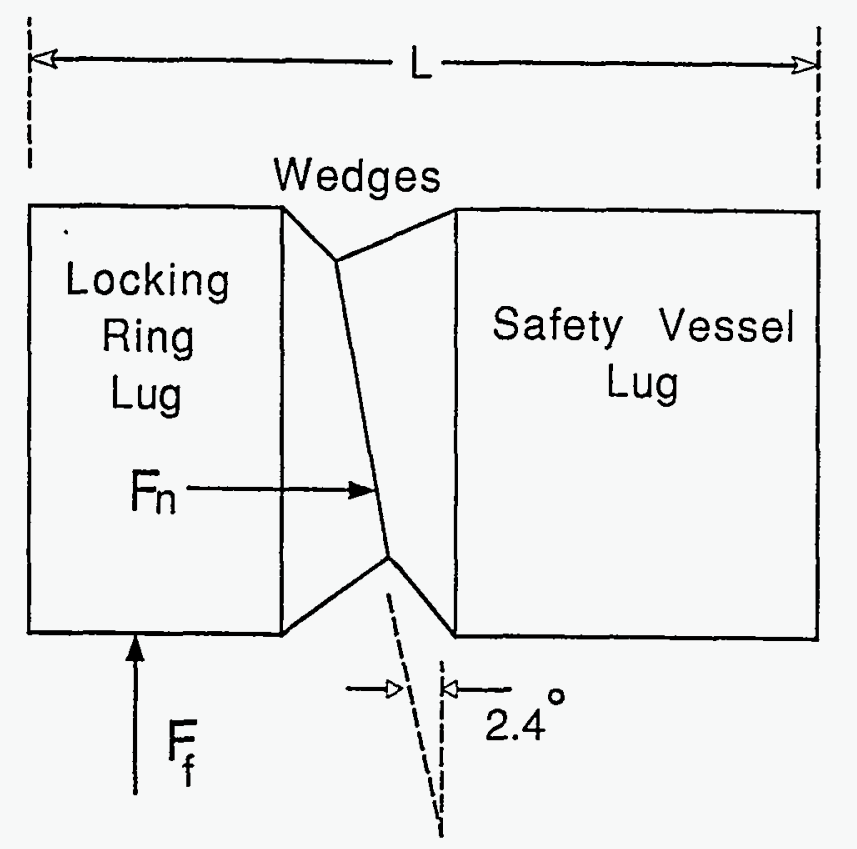

Figure 23: Schematic of locking ring tightening mechanism.

force of $F_{f}=281 \mathrm{lbs}$. The compressive strain in the lugs/wedges is $\epsilon=0.0000036$ corresponding to a small compressive stress of $\sigma=109 \mathrm{psi}$. We feel this preload stress is insignificant and probably conservative because we neglected the force needed to compress the o-ring. Thus we did not compressively preload the locking ring mechanism prior to pressurization and impact.

\subsection{Confinement Vessel Velocity and Safety Vessel Pressur- ization}

The gas dynamics analysis described in Appendices A and B was used to calculate the pressure history in the safety vessel and initial impact velocity of the confinement vessel. Predicted chamber pressures, confinement vessel displacement, and velocity histories are given in Figures 24-26. The initial conditions and chamber volumes used in the analysis were previously given in Table 1 . The pressure in the confinement and safety vessels equalizes to about $810 \mathrm{psi}$ in $6.5 \mathrm{msecs}$. At this time, the gas dynamics analysis predicts a confinement vessel displacement of about 5.5 inches and a steady vessel velocity of $1342 \mathrm{in} / \mathrm{sec}$. This displacement is just greater than the initial distance between the confinement vessel and protective channel, which is about 5 inches. This suggests that the pressure in the safety vessel will equalize to nearly $810 \mathrm{psi}$ before the confinement vessel impacts the channel.

In our finite element analysis, we applied the safety vessel pressure history from Figure 24 to the safety vessel and protective channel for $6.5 \mathrm{msecs}$, then we held the pressure constant at $810 \mathrm{psi}$ until the end of the calculation. During the first 6.5 msecs, no pressure or velocity was applied to the confinement vessel. At 6.5 msecs, we applied an initial velocity of 1342 in/sec to the confinement vessel and allowed it to impact the channel. The calculation was run until the velocity of the confinement 


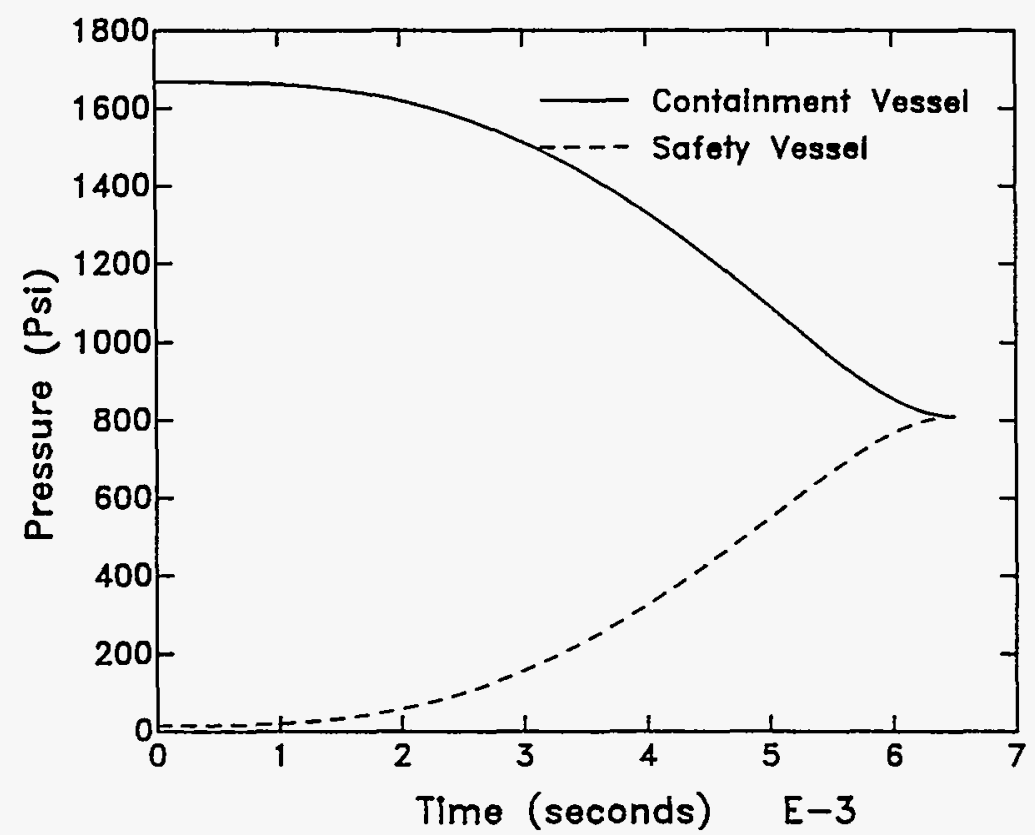

Figure 24: Pressure histories in the confinement and safety vessels.

vessel was reduced to zero.

\subsection{Results of the Finite Element Analysis}

Two finite element analyses were performed. In the first analysis, the channel was tied to the left safety vessel using a tied interface, to simulate a weld that does not break during pressurization and impact. In the second analysis, the channel was initially tied to the left safety vessel to simulate a weld that does not break during pressurization. However, we replaced the tied interface with a sliding-with-voids interface following initial pressurization to allow relative sliding/separation between the channel and vessel. This was done to simulate a weld that breaks during impact because this is a possible failure mode given the minimal weld line shown in the blueprints provided by Melco Steel. However, the two analyses performed with and without weld line breakage did not significantly differ, so only the analysis without weld line breakage is presented here.

The deformed configuration of the mesh at various time intervals is given in Figures 27 through 29. The deformed configuration just prior to impact is shown in Figure 27 at 6.5 msecs. At this time, application of the applied pressure history is complete and the pressure is held constant at 810 psi. A 0.065 gap forms between the left and right hemispheres of the safety vessel. The gap is not readily visible in Figure 27 without magnification. Our estimate of the initial compression of the o-ring is $1 / 16$ inch, which indicates that the gap is just large enough to allow gas to escape to the atmosphere. At this time, the minimum principal stress in the wedges is 51 ksi (compressive), which exceeds the estimated yield strength of 40 ksi provided by 


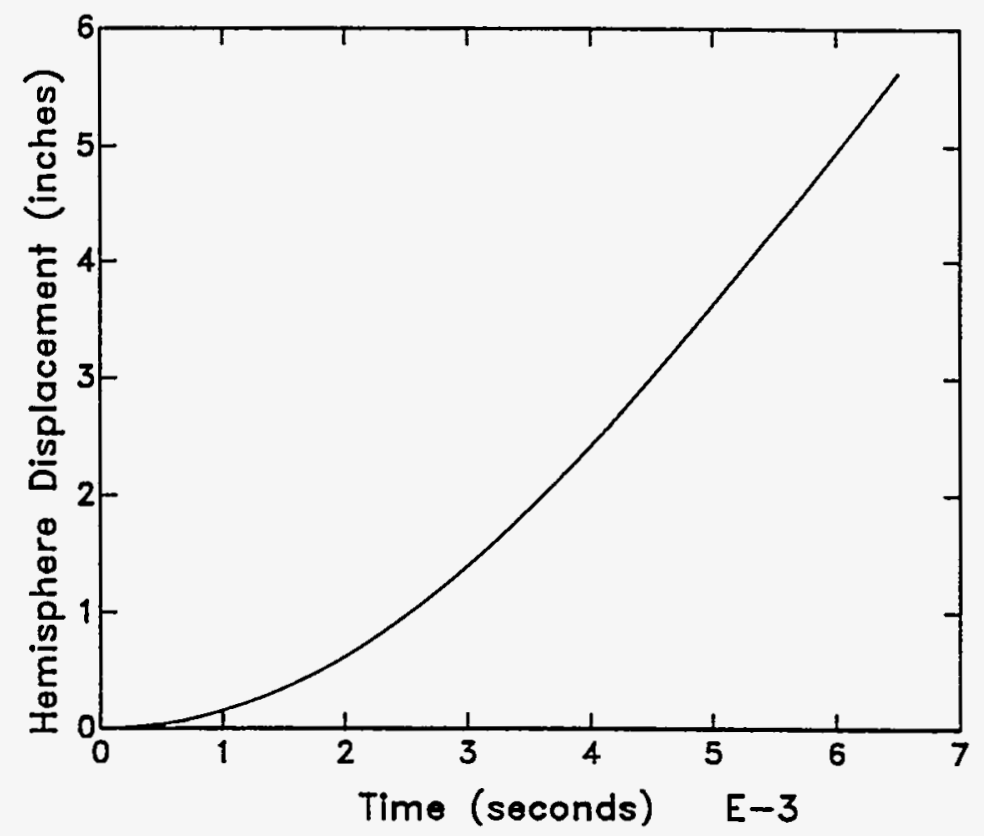

Figure 25: Confinement vessel displacement history.

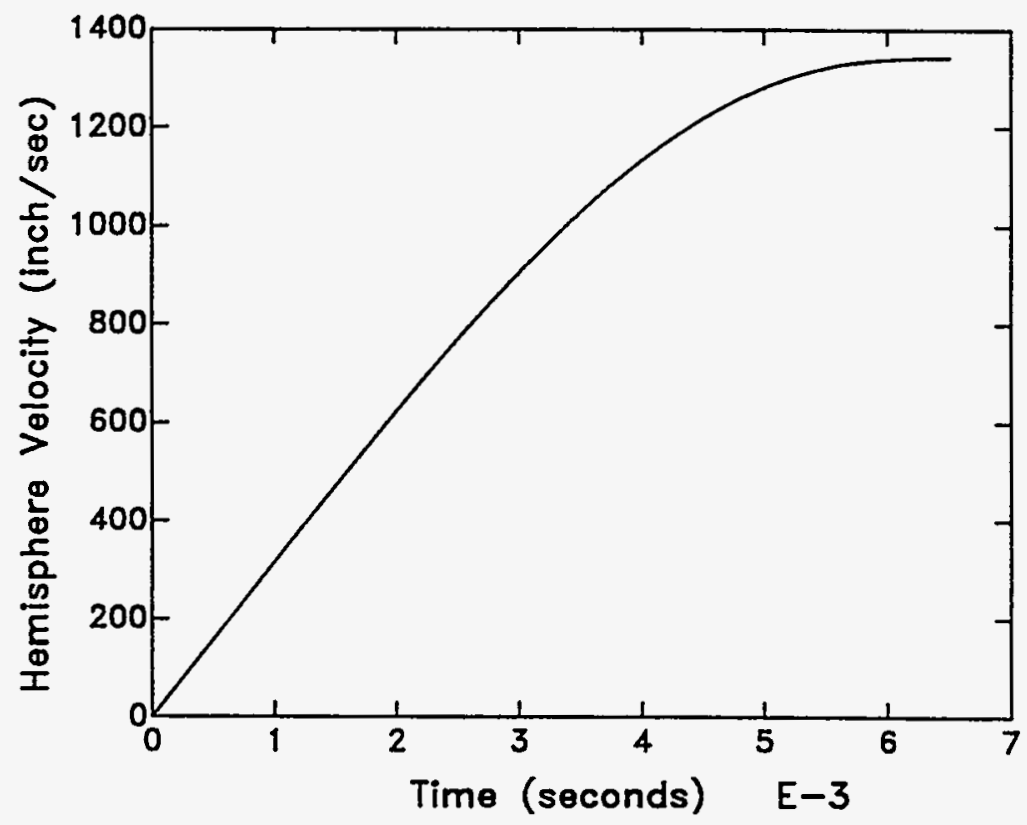

Figure 26: Containement vessel velocity history. 




Figure 27: Deformed configuration at 6.5 msecs just prior to impact.

LANL for the cold rolled steel. It is possible that yielding of the compressive wedges contributes to the formation of a larger gap than would otherwise be predicted with elastic wedges.

When the confinement vessel impacts the protective channel, it causes the channel and left safety vessel to slide relative to the right safety vessel. This is because the channel is attached to the left safety vessel, but not the right safety vessel. The deformed configuration at 7.6 msecs is shown in Figure 28 when the underside of the channel impacts the right safety vessel. A visible gap up to 0.27 inches wide forms between the left and right halves of the safety vessel. Although an o-ring is located between the left and right vessels approximately midway through the vessel thickness, the size of the gap is greater than 1/16-inch (our estimate of the maximum compression of the o-ring). This indicates that gaseous detonation products have an escape path to the atmosphere.

The deformed configuration of the full mesh at 9.6 msecs is shown in Figure 29 when the velocity of the impacting confinement vessel has decelerated to zero. By this time, the maximum gap between the left and right vessels has grown to about 0.6 inches. The full extent of this gap is visible in Figure 30 for the deformed configuration of the safety vessel hemispheres. Separation is apparent over a substantial portion of the quarter circumference. At this time, the minimum principal stress in the wedges is $191 \mathrm{ksi}$ (compressive), well above the yield strength recommend by LANL. 


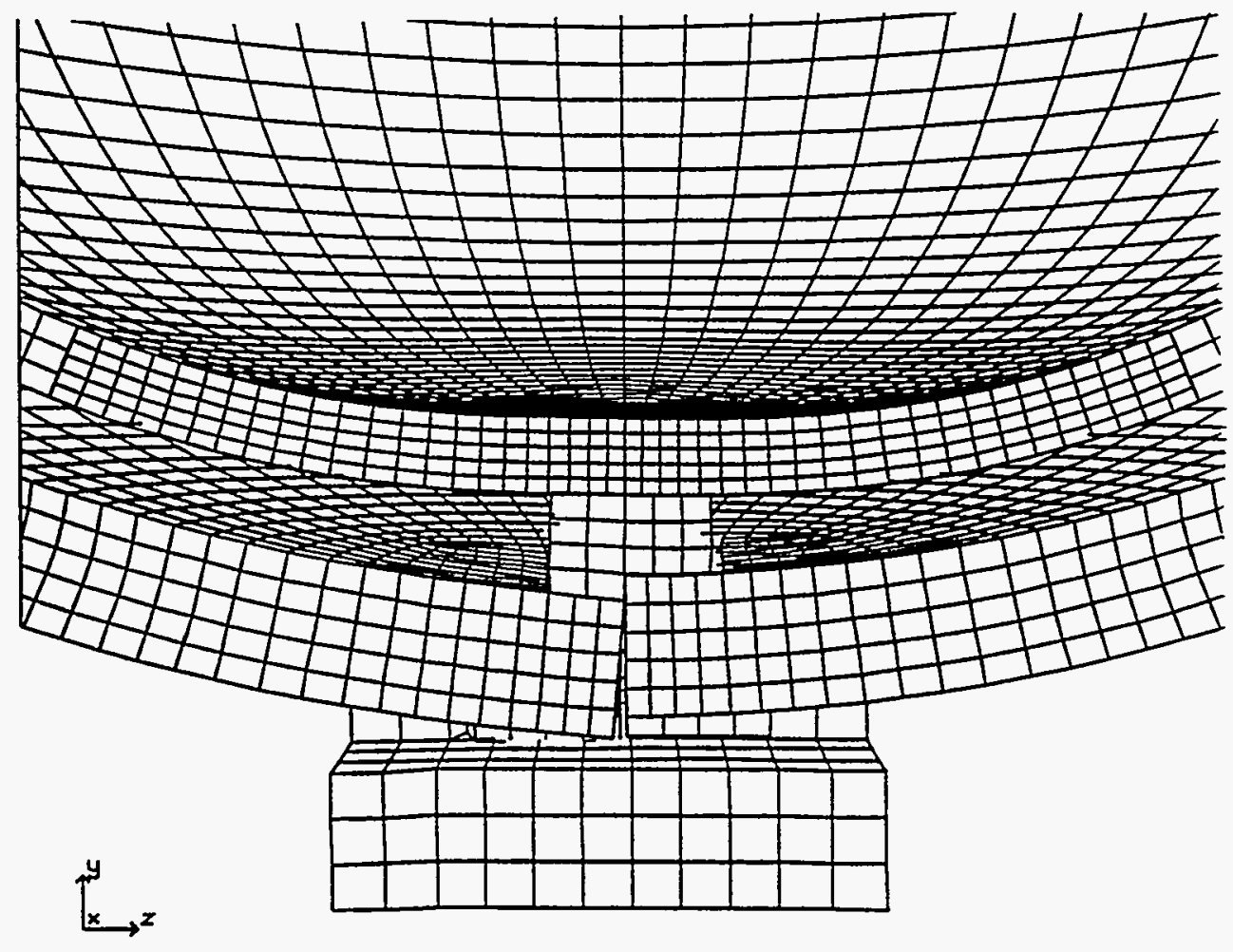

Figure 28: Deformed configuration at 7.6 msecs when underside of channel impacts right safety vessel. 


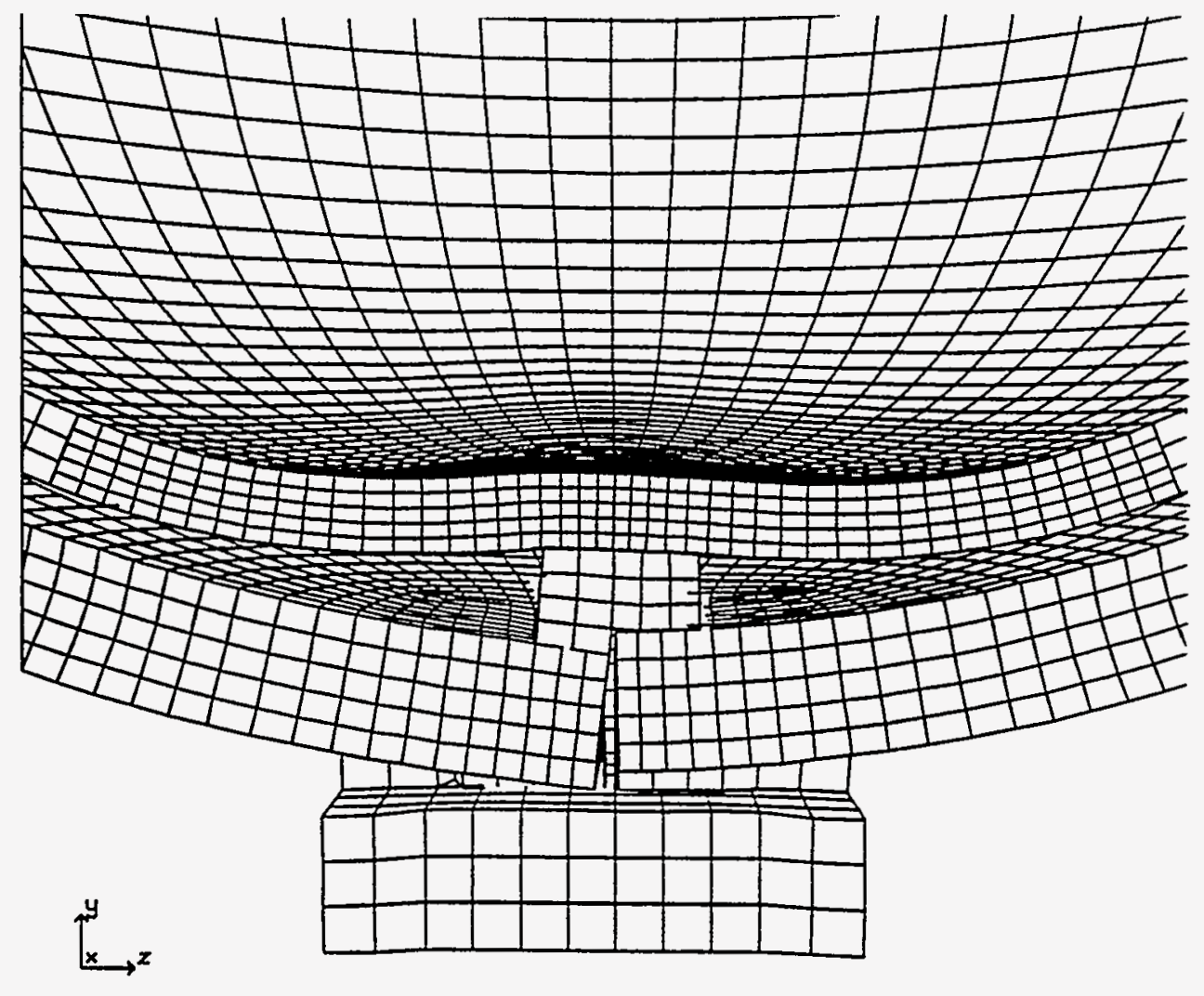

Figure 29: Deformed configuration at 9.6 msecs when velocity of confinement vessel has decelerated to zero.

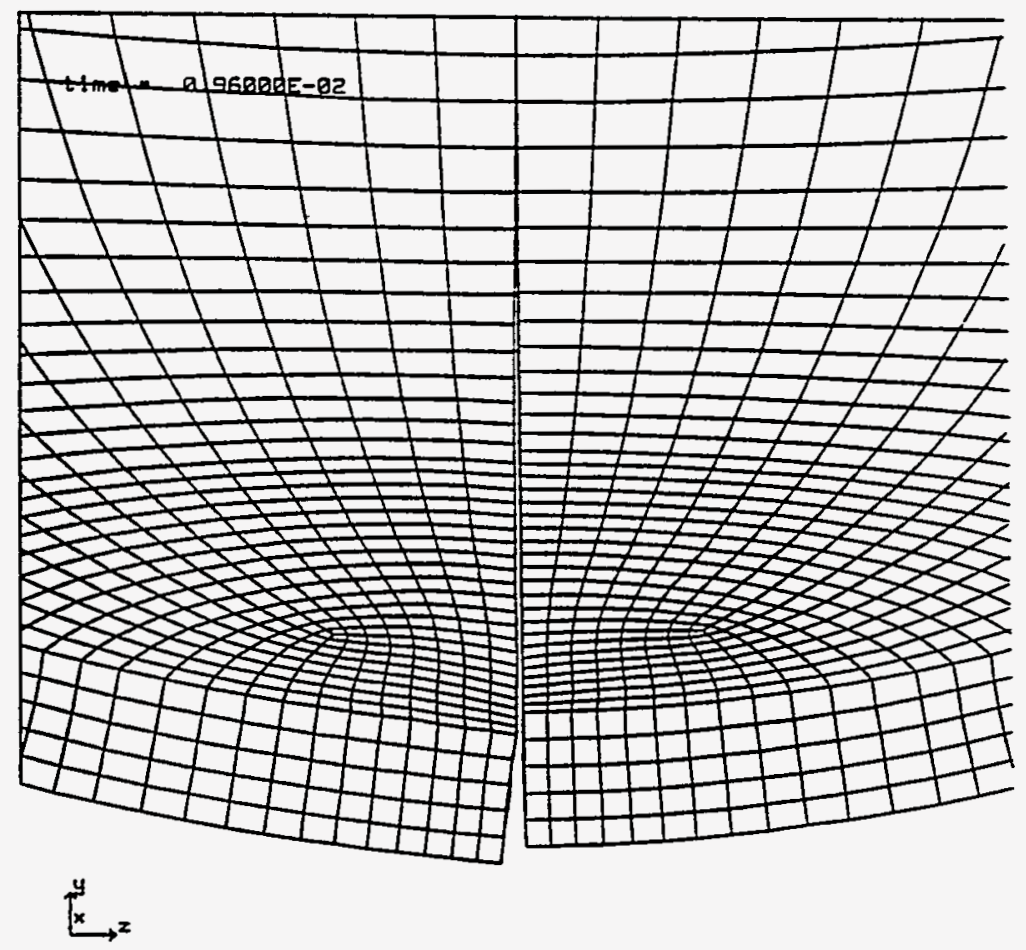

Figure 30: Deformed configuration of the safety vessel at 9.6 msecs. 


\subsection{Summary and Conclusions}

Our analyses indicate that the locking ring mechanism will not prevent gaseous detonations products from escaping to the atmosphere during catastrophic failure of the confinement vessel. This is because the confinement vessel hemisphere impacts a protective channel connected to only one half of the safety vessel. This causes relative sliding and separation to occur between the two halves of the safety vessel.

One conservative assumption used in the analyses was that we did not take into account the energy required to break the confinement vessel into two hemispheres along the weld line. If we had, the initial kinetic energy of the confinement vessel would be reduced by an amount equal to the energy required to break the weld. No experiments have been done to establish the energy required to break the weld.

Another conservative assumption is that we used the $40 \mathrm{ksi}$ yield strength recommended by LANL for the cold rolled steel of the wedges. This value is substantially less than the 83 to 112 ksi yield strength recommended by Melco Steel. An additional calculation could readily be performed to determine if modeling less yielding in the wedges leads to less separation between the safety vessel hemispheres. If so, then further tests should be done to understand the difference between LANL's and Melco's recommended values.

We also assumed that the confinement vessel impacts the protective channel uniformly in the vertical y-direction. Another impact scenario is at-angle impact. Based on LANL's drawings, we expect the confinement vessel to impact the upper right surface of the channel first. This is the side of the channel not connected to the safety vessel, as schematically shown in Figure 31. With at-angle impact, the momentum of the confinement vessel in the vertical $y$-direction is less that previously analyzed, so we'd expect less relative sliding between the left and right vessels. However, when the right side of the channel is impacted by the confinement vessel, the weld on the left side will probably break as the channel bends. The response calculated for atangle impact could be quite different than the response already calculated for uniform impact.

To more accurately assess the containment capability of the safety vessel, we recommend that an additional analysis be performed with at-angle impact using the quarter-symmetric model. This should be done to determine if at-angle impact is more or less severe than uniform impact. Once the at-angle analysis is complete, we recommend evaluating the protective channel for designs that prevent the unsatisfactory gap formation. For example, an additional metal strip could be welded to the right safety vessel that fits snugly beneath the channel. In this way, the impact load is more evenly distributed to the left and right vessels. 


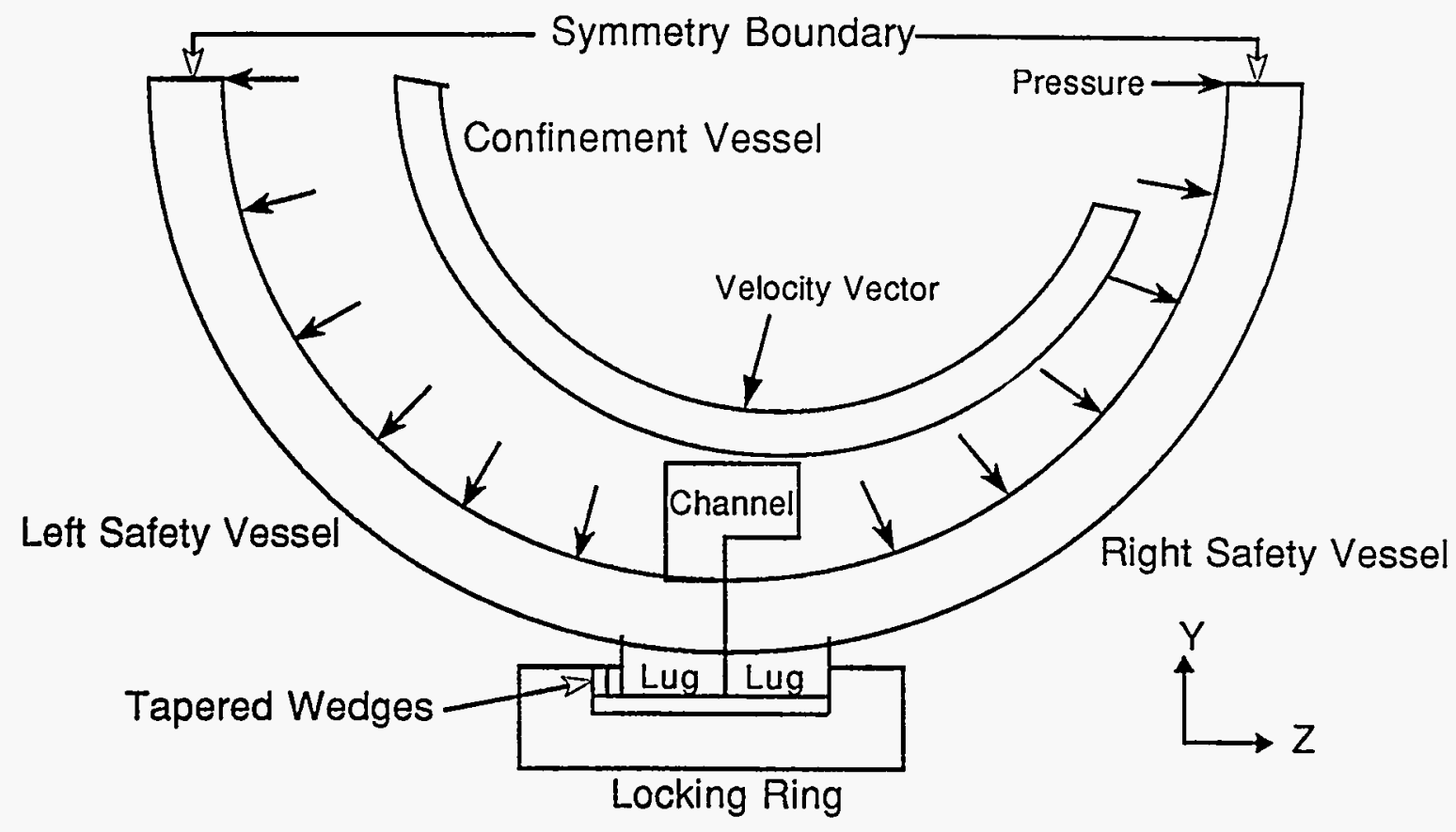

Figure 31: Schematic of at-angle impact between confinement vessel and channel. 


\section{References}

[1] Moir, D.C. "Safety Analysis of the M-2 Confinement Systems," Los Alamos Scientific Laboratory, University of CA, Los Alamos, New Mexico, TM-264, October, 1979.

[2] Baker, W.E., "Blast and Fragments from Bursting Pressure Vessels," Southwest Research Inst., San Antonio, Texas, ASME, Pressure Vessel and Piping Division, PVP V. 82, pps. 51-66.

[3] Yamamasu, J. and H. Miyamoto, "On High Strain Rate Fragmentation of a Closed Vessel," Proceedings of the Twentyseventh Japan Congress on Materials Research, The Society of Materials Science, Kyoto, Japan, 1984, pps. 39-45.

[4] Coleman, M. et. al. "A Review of Energy Release Processes From the Failure of Pneumatic Pressure Vessels," General Physics Corp, Cap Canaveral Air Force Station, Florida, prepared for Kennedy Space and Missile Center, Air Force Systems Command, Patrick Air Force Base, Florida, FO8606-86-C-0030, August 1988.

[5] Cain, Sharp, and Coleman, "Pressure Vessel Burst Test Program, Progress Paper No. 2," General Physics Corp, Cap Canaveral Air Force Station, Florida, prepared for Eastern Space and Missile Center, Patrick Air Force Base, Florida, June, 1991.

[6] Baum, M.R. "Velocity of Missiles Generated by the Disintegration of GasPressurized Vessels and Pipes," Central Electricity Generating Board, Berkeley Nuclear Labs, England, CEGB-TPRD/B-0217/N83, March, 1983.

[7] Bartenev, A.M., et. al. "Kinematics of Fragments from Disintegrating Pressure Vessels," Fluid Dynamics, Vol. 23, No. 6, Nov-Dec, 1989, pps. 874-878. 


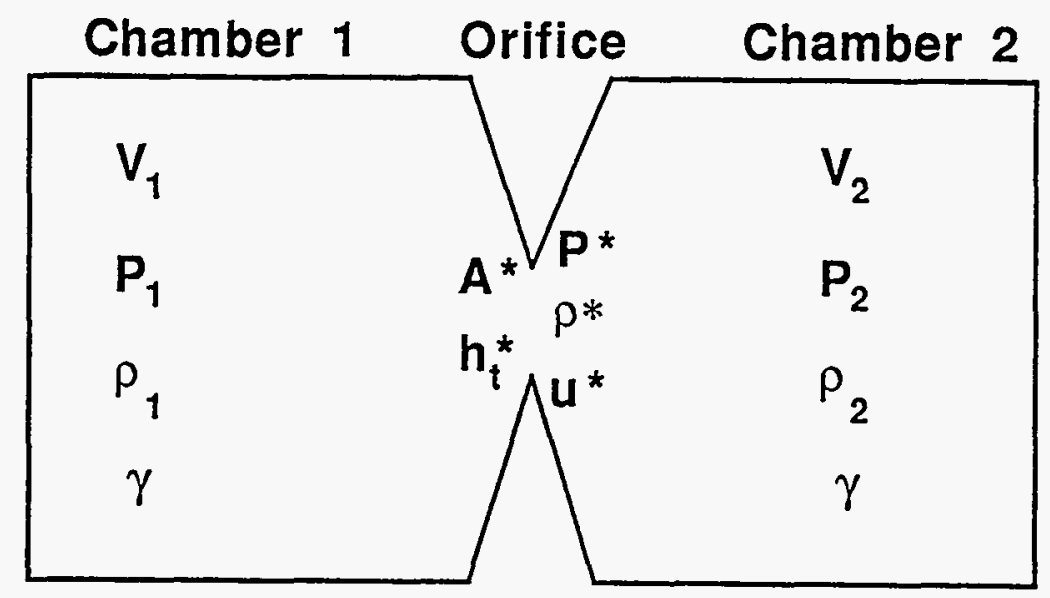

Figure 32: Properties and geometry for gas dynamics analysis.

\section{A Gas Dynamics Analysis Predictions}

Gas dynamics analyses ${ }^{5}$ was performed to determine the pressure history in the safety vessel, and intial velocities of the penetrating nozzle and impacting hemisphere. We analyzed the one-way flow of gas from one chamber to a second chamber through an orifice of variable area. A schematic of the idealized geometry is shown in Figure 32. The chamber volumes are designated $V_{1}$ and $V_{2}$ and the orifice area is designated $A^{*} . V_{1}$ is the volume of the containment vessel while $V_{2}$ is the difference in volume between the safety vessel and the containment vessel. The orifice area is the opening between the safety vessel and the containment vessel caused by fracture and acceleration of the nozzle or hemisphere. The orifice area is initially zero and increases as the nozzle or hemisphere separates from the remaining containment vessel. For the nozzle penetration analysis, we modeled the orifice area as the surface area of a cylinder. The radius of the cylinder is the radius of the nozzle and the height of the cylinder is the separation distance between the nozzle and the containment vessel. The acceleration history of the nozzle is calculated from the difference in pressure in each chamber. For the hemisphere analysis, we also modeled the orifice area as the surface area of a cylinder. The radius of the cylinder is the radius of the containment vessel hemisphere.

It is assumed that the thermodynamic properties are uniform throughout each chamber. These properties include the pressure $P$, the density $\rho$, and the total enthalpy $h_{t}$. The subscripts ' 1 ' and ' 2 ' designate the properties in each chamber. The superscript ' $*$ ' designates the properties at the orifice. The velocity at the orifice is $u^{*}$.

We used a control volume approach and conservation of mass for compressible

\footnotetext{
${ }^{5}$ These analyses are loosely based on the theory of the GASLEAK code developed at SRI International.
} 
flow from chamber 1 to chamber 2 to obtain the following rate equations for density:

$$
\begin{aligned}
& \frac{\partial \rho_{1}}{\partial t}=-\frac{\rho^{*} u^{*} A^{*}}{V_{1}} \\
& \frac{\partial \rho_{2}}{\partial t}=+\frac{\rho^{*} u^{*} A^{*}}{V_{2}}
\end{aligned}
$$

We used conservation of energy for a system with no head addition or loss, no body forces, and no frictional forces (nonviscous) to obtain the following rate equations for pressure:

$$
\begin{aligned}
& \frac{\partial P_{1}}{\partial t}=\gamma h_{t}^{*} \frac{\partial \rho_{1}}{\partial t} \\
& \frac{\partial P_{2}}{\partial t}=\gamma h_{t}^{*} \frac{\partial \rho_{2}}{\partial t}
\end{aligned}
$$

The pressure history in each chamber was calculated from equations 4 through 7 given the initial chamber pressures and densities and using the following incremental updates:

$$
\begin{aligned}
& P_{1_{n+1}}=P_{1_{n}}+\left.\frac{\partial P_{1}}{\partial t}\right|_{n} \Delta t \\
& P_{2_{n+1}}=P_{2_{n}}+\left.\frac{\partial P_{2}}{\partial t}\right|_{n} \Delta t
\end{aligned}
$$

Here the subscript ' $n$ ' represents the $\mathrm{n}^{\text {th }}$ time step in the incremental analysis and $\Delta t$ is the time step.

To update the pressure in each chamber, the orifice orifice conditions $\left(\rho^{*}, h_{t}^{*}, u^{*}\right)$ must be calculated at each time step. We assume that the density at the orifice, $\rho^{*}$, is given by the isentropic relation:

$$
\frac{\rho^{*}}{\rho_{1}}=\frac{P^{* 1 / \gamma}}{P_{1}}
$$

Thus the orifice pressure $P^{*}$ must be known to calculate the orifice density. We assume that the orifice pressure depends on the pressure ratio between chambers 1 and 2. If the pressure ratio $\left(P_{2} / P_{1}\right)$ is small enough then the flow will be choked (sonic) at the orifice. The minimum pressure attainable at the orifice is for choked flow and is termed the critical pressure. The critical pressure is designated as $P_{c}$ and is equal to:

$$
P_{c}=P_{1}\left(\frac{2}{\gamma+1}\right)^{\frac{\gamma}{\gamma-1}}
$$

If the pressure in chamber 2 is less than $P_{c}$, then we assume the flow is choked and the pressure at the orifice is set equal to the critical pressure: $P^{*}=P_{c}$. Otherwise the pressure at the orifice is set equal to the pressure in chamber 2: $P^{*}=P_{2}$. 
We assume quasi-steady flow to calculate the total enthalpy at the orifice, i.e. the total enthalpy is constant, or conserved along a streamline. Thus the total enthalpy at the orifice is equal to the total enthalpy in chamber 1 , as follows:

$$
h_{t}^{*}=\frac{\gamma}{\gamma-1} \frac{P^{*}}{\rho^{*}}+\frac{1}{2} u^{* 2}=\frac{\gamma}{\gamma-1} \frac{P_{1}}{\rho_{1}}
$$

The velocity at the orifice is readily calculated from equations 10 and 12 , as follows:

$$
u^{*}=\left[\frac{2 \gamma}{\gamma-1} \frac{P_{1}}{\rho_{1}}\left(1-\frac{P^{*} \frac{\gamma-1}{\gamma}}{P_{1}}\right)\right]^{1 / 2}
$$

\section{B Validation of the Gas Dynamics Analysis.}

We obtained initial velocity estimates for both the colliding hemisphere and nozzle penetrator in the Task 2 safety vessel calculations from the gas dynamics analysis given in Appendix A. To ensure confidence in our initial velocity estimates, we correlated our gas dynamics analysis with the vessel flight test discussed in Reference [1]. This was done by comparing the vessel velocity calculated from the gas dynamics analysis with that measured during the test. Our estimate of $1369 \mathrm{in} / \mathrm{sec}$ is in excellent agreement with the experimental value of $1319 \mathrm{in} / \mathrm{sec}$, thus validating our analysis method. Details of the flight test and verification calculation are given in the following paragraphs.

The vessel flight test consists of a charge detonated inside a spherical confinement vessel. The two hemispheres of the vessel were tack-welded together. The upper half of the vessel was free to $\mathrm{fly}$ in the air while the lower half of the vessel was positioned to impact a target. A high speed camera was used to view the experiment. The flight time and maximum vertical height of the upper hemisphere were used to estimate the initial hemisphere velocity.

We performed a gas dynamics analysis of the vessel flight test to calculate the hemisphere velocity. We analyzed the flow of gas from the confinement vessel (chamber 1) to the atmosphere (chamber 2) through an orifice of variable area. We assumed that the orifice area is that of a cylindrical surface and increases as the two hemispheres of the fractured vessel separate from each other. This allows the gases in the containment vessel to flow into the atmosphere. The acceleration history of the hemisphere was calculated from the the mass of the hemisphere and the difference in pressure between the containment vessel and the atmosphere.

The initial conditions and geometry of each chamber are given in Table 3. The initial pressure in chamber 1 is the quasi-static pressure from a $5 \mathrm{lb}$ charge. The initial volume of chamber 1 is the volume within the spherical containment vessel. The radius of the vessel is 18 inches and the wall thickness is 1 inch. We estimated a mass of $3.366 \mathrm{lb}-\mathrm{s}^{2} /$ in for the hemisphere. The initial pressure in chamber 2 is atmospheric pressure, while the volume of chamber 2 is infinite.

Chamber pressures, hemisphere displacement, and velocity histories are given in Figures 33-35. The pressure in the vessel decays to atmospheric pressure in about 9 
Table 3: Initial conditions and chamber geometry used in the gas dynamics analysis of the colliding hemisphere experiment.

\begin{tabular}{|l|c|c|}
\hline & Chamber 1 & Chamber 2 \\
\hline \hline $\mathrm{V}\left(\mathrm{in}^{3}\right)$ & 24,429 & $\infty$ \\
$\mathrm{P}(\mathrm{psi})$ & 1093 & 11.6 \\
$\rho\left(\mathrm{lb} / \mathrm{in}^{3}\right)$ & $2.05 \mathrm{e}-04$ & $4.17 \mathrm{e}-05$ \\
$\gamma$ & 1.4 & 1.4 \\
\hline
\end{tabular}

msecs. At this time, the hemisphere displacement is over 9 inches and the hemisphere velocity is at a maximum value of $1369 \mathrm{in} / \mathrm{sec}$. A hemisphere velocity of $1319 \mathrm{in} / \mathrm{s}$ $(33.51 \mathrm{~m} / \mathrm{s})$ was measured from the flight test in Reference [1]. The calculated velocity agrees with the measured velocity within $4 \%$, which is excellent agreement. 


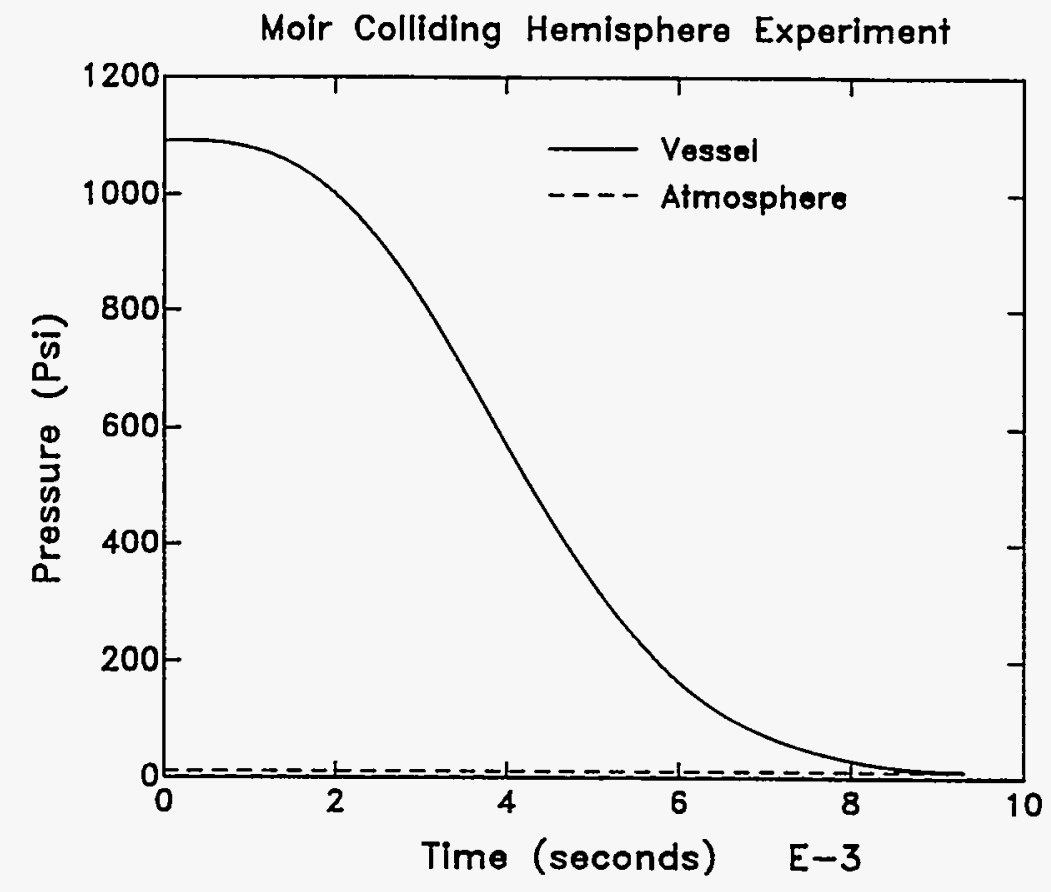

Figure 33: Pressure history in the containment vessel.

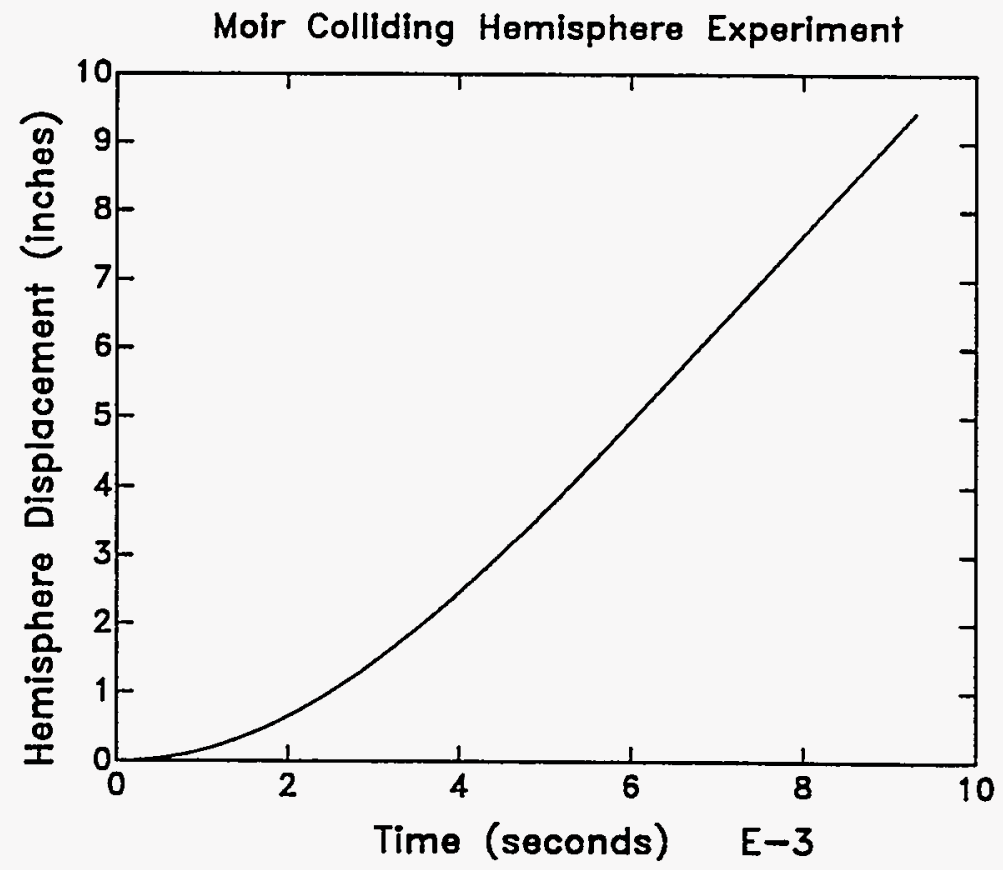

Figure 34: Hemisphere displacement history. 


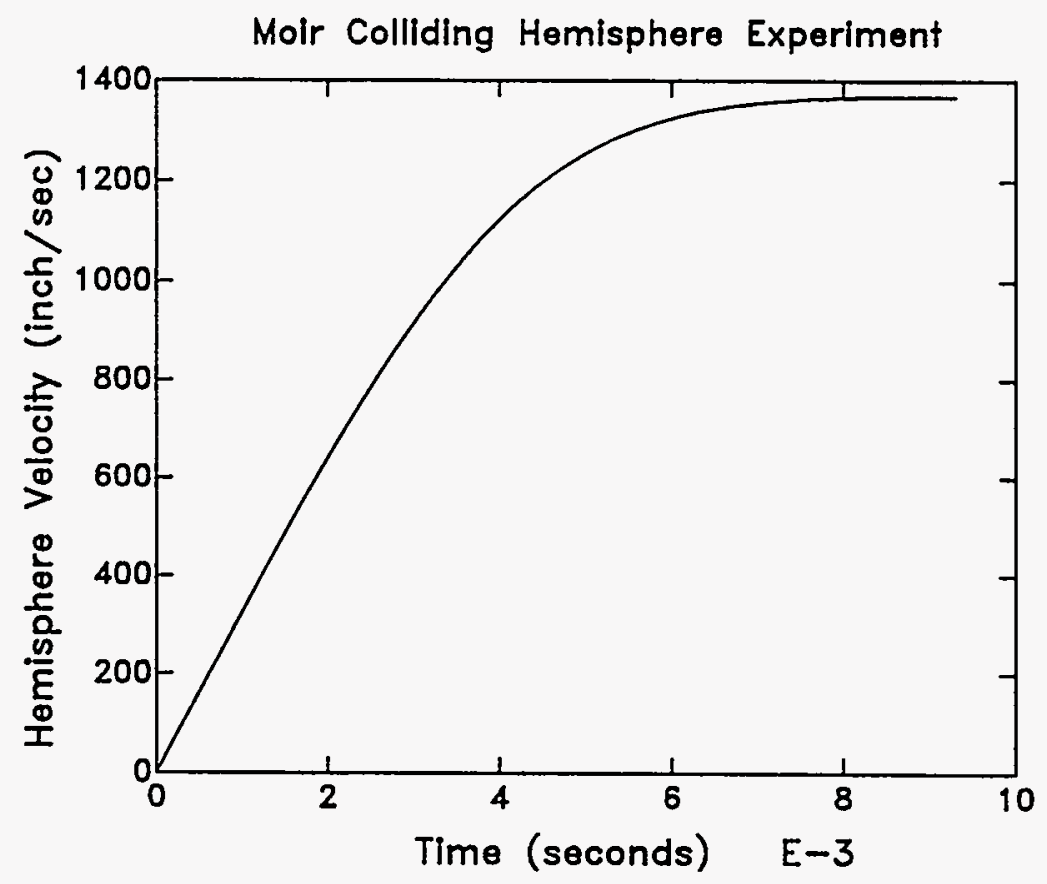

Figure 35: Hemisphere velocity history. 